\title{
Femoroasetabular sıkışma sendromunda bilgisayarlı tomografi ve dijital dinamik değerlendirme
}

\section{Computed tomography and dynamic digital evaluation in the diagnosis of femoroacetabular impingement syndrome}

\author{
N. Reha Tandoğan ${ }^{1}$, Asım Kayaalp ${ }^{1}$, Ş. Eser Şanverdi ${ }^{2}$ \\ 'Çankaya Ortopedi ve Ortoklinik, Ankara \\ ${ }^{2}$ Çankaya Ortopedi ve İntegra Görüntüleme Merkezi, Ankara
}

\begin{abstract}
Femoroasetabular sıkışma (FAS) sendromunun tanısı, ameliyat öncesi ve sonrası değerlendirilmesinde bilgisayarlı tomografi (BT), yüksek iyonizan radyasyon dozu gerektirmesine rağmen, çok yararlı bilgiler sağlar. Kalça ekleminin üç boyutlu morfolojisinin değerlendirilmesi yanında, objektif ölçümler de yapılabilir. Femoral anteversiyon, asetabular versiyon, lateral merkez kenar açısı, alfa ve beta açıları, başboyut ofseti ve omega alanı gibi ölçümler, eklemin dizilimi ve yönelimi hakkında bilgiler verir; cam ve pincer lezyonunun objektif olarak ortaya konmasını sağlar. BT kesitlerinden elde edilen görüntülerin bilgisayar yazılımları ile işlenmesi sonrasında, üç boyutlu dinamik incelemeler yapılabilir. Bu dinamik incelemeler ile, hangi hareket açıklığında ve nerede sıkışma ortaya çıktığı, yüksek doğruluk oranında saptanabilir. Bu verilerden haritalama yapılarak, rezeksiyon miktarı ve bölgesi planlanır ve rezeksiyon sonrası durum simüle edilebilir. BT artrografi kıkırdak ve labrum lezyonlarının tanısında yardımcı olabilir. Spina iliaka anterior inferior sıkışması ve iskio-femoral sıkışma gibi ektra-artiküler sıkışma sendromlarında da BT ile objektif değerlendirme yapılabilir. Son olarak, FAS cerrahisi uygulanmış ve semptomları olan hastalarda BT, yeterli rezeksiyon yapılıp yapılmadığının doğrulanması açısından yararlıdır. Bütün radyolojik bulgular klinik yakınmalar ile birlikte değerlendirilmelidir, zira normal bireylerde FAS morfolojisinin bir veya birden fazla bulgusunun varlığı oldukça önemli oranda görülebilir.
\end{abstract}

Anahtar sözcükler: femoroasetabular sıkışma; bilgisayarlı tomografi; kalça eklemi
Computed tomography (CT) provides valuable information in the diagnosis, pre- and post-operative evaluation of femoroacetabular impingement (FAI) syndrome, although it requires high doses of ionizing radiation. The 3 dimensional morphology of the hip joint can be accurately assessed and the typical cam and pincer lesions can be delineated. Several measurements including femoral anteversion, acetabular version, lateral center-edge angle, alpha and beta angles, femoral head-neck offset and omega area are helpful in the objective quantification of the impingement. The data from CT scans can be digitized with dedicated software to obtain dynamic images. These digital dynamic evaluations accurately describe the area and extent of impingement in the hip joint. This data can then be used to plan the amount of surgical resection and simulate the final post-operative situation. CT arthrography may be helpful for the diagnosis of accompanying chondrolabral lesions. CT can also objectively demonstrate extraarticular causes of hip impingement such as subspine and ischio-femoral impingement. Finally, CT is a useful tool to evaluate patients with residual symptoms following surgery for FAI. All radiographic findings should be closely correlated with clinical symptoms since a significant number of asymptomatic cases may have one or more signs of FAl morphology.

Key words: femoroacetabular impingement; computed tomography; hip joint

bir avantajdır. Buna karşılık, maliyeti ve hastanın yüksek iyonizan radyasyona maruz kalması, BT'nin dezavantajlarıdır. Canham ve ark. ${ }^{[1]}$, FAS sendromu cerrahisi geçiren bir hastanın tanısal işlemler ve cerrahi sırasında toplam 490 milirem iyonizan radyasyona maruz kaldığını ve yaşam boyu kanser riskinin \%0,025 arttığını bulmuşlardır.Bu nedenle, FAS tanısında kullanılan görüntüleme yöntemleri sırasında radyasyon miktarını azaltmak için önlemler alınmalıdır.

- İletişim adresi: Prof. Dr. N. Reha Tandoğan, Cinnah caddesi 51/4 Çankaya, Ankara

Tel: 0312 - 4390206 e-posta: rtandogan@ortoklinik.com

- Geliș tarihi: 10 Ocak2016 Kabul tarihi: 10 Ocak2016 


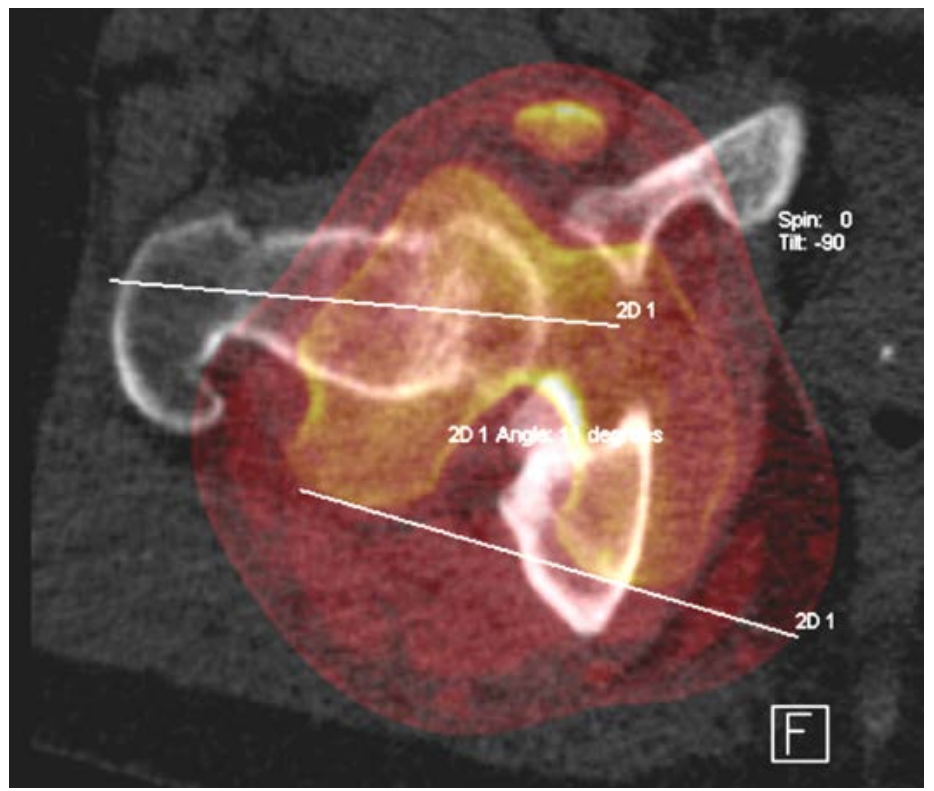

Şekil 1. BT ile femoral anteversiyon ölçümü.

\section{FAS SENDROMU GÖRÜNTÜLEMESINDE BT TEKNiĞi}

FAS sendromunu BT ile görüntülemede, öncelikle krista iliaka ile femur diyafiz orta kesimini içine alan anterior-posterior topogram elde edilir. Bu görüntü üzerinden, asetabulum çatısı düzlemi ile trokanter minör düzlemine dek aksiyel görüntüleme yapılacak plan belirlenir. İnceleme, kemik algoritması ile gerçekleştirilmelidir. X ışını dozu, hastanın yumuşak doku kalınlığı ile değişmekle birlikte, genellikle 120-140 kV, 250-300 $m A$ ve $0,8-1$ rotasyon süresi yeterlidir. Kesit kalınlığı maksimum 5-6 mm seçilmeli, ince kesit rekonstrüksiyon ve $3 \mathrm{~B}$ görüntüleme için kesit aralığı bırakılmamalıdır. Rekonstrüksiyonlar, 1-2 mm kesit kalınlığı ve maksimum $1 \mathrm{~mm}$ kollimasyon ile gerçekleştirilmelidir. Daha kalın kesitler ve kolimasyon, reformat görüntülerde basamaklanma artefaktına yol açar. Rekonstrükte edilen kesitlerin kemik penceresinde (Kernel 30) ile filtrelenmesi, kortikal keskinliğin korunması açısından önemlidir. İnceleme sırasında intravenöz kontrast madde kullanmaya gerek yoktur. ${ }^{[2]}$

\section{BT ILE YAPILMASI GEREKEN STANDART ÖLÇÜMLER}

Direkt radyografi ve manyetik rezonans (MR) görüntüleme kullanılarak yapılan bütün ölçümler, BT ile de yapılabilir. Alfa-açısı, baş-boyun ofseti, asetabular versiyon, femoral anteversiyon, lateral CE (center-edge) açısının ölçümü, BT değerlendirmesinin rutin bir parçası olmalıdır. Eklem dışı FAS nedenlerinden spina iliaka anterior inferior sıkışması, trokanter minör ile iskium arası sıkışma (iskio-femoral sıkışma) gibi patolojilerin değerlendirilmesinde de BT kullanımı değerlidir. Cam tipi sıkışmada, femur boynunun 3B anatomisini BT kadar iyi gösteren bir yöntem yoktur. Artro-BT'nin kullanımı, kalça eklemindeki ikincil labrum ve kıkırdak lezyonlarının tanısında değerlidir. BT görüntülerinden elde edilen 3B hareketli bilgisayar modellemeleri, hastalığın dinamik değerlendirilmesini sağlar. Geliştirilmiş bilgisayar simülasyonları ile sıkışmanın yeri ve boyutları hakkında ayrıntılı bilgi edinilebileceği gibi, rezeksiyon miktarı ve bölgesinin planlanması konusunda da dinamik değerlendirme önemli ipuçları verir.

FAS sendromu değerlendirilmesinde, aşağıdaki ölçümler rutin olarak yapılmalıdır. Heyworth ve ark. ${ }^{[3]}$, BT ile elde edilen bulguların ameliyat sırasında saptanan bulgular ile doğrudan korele olduğunu bulmuşlardır.

\section{Femoral Anteversiyon}

Aksiyel kesitlerde diz eklemi superioru ve femur boynundan geçen kesitlerin süperpoze edilmesi ile yapılan bir ölçümdür (Şekil 1). Posterior femur kondillerini birleştiren çizgi ile femur boynu uzun ekseni arasındaki açıdır. Koerner ve ark. ${ }^{[4]}, 417$ olgunun incelenmesinde, erişkin femoral anteversiyon derecesini $8,9 \pm 9,7^{\circ}$ olarak bulmuşlardır. Yazarlar, cinsiyet yönünden bir fark bulmazken, özellikle siyah ırktan erkeklerin \%6'sında, 


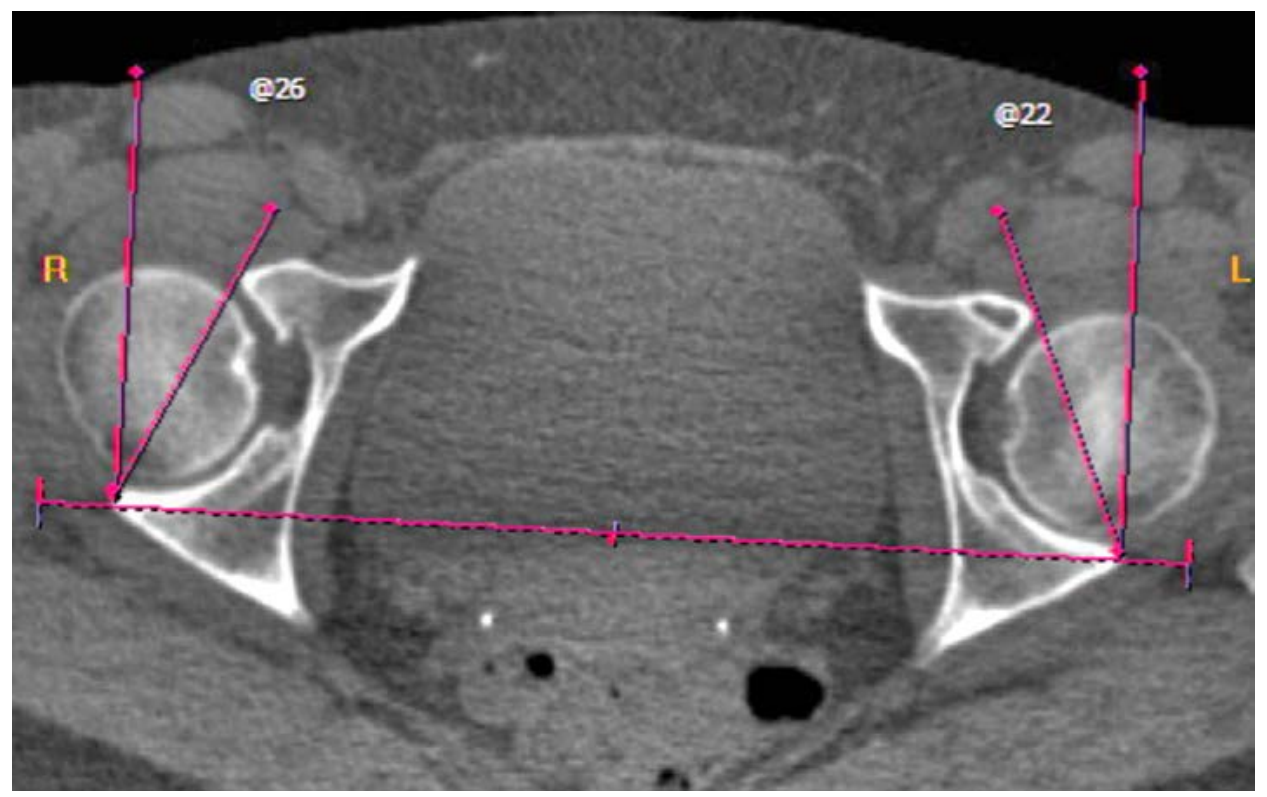

Şekil 2. Asetabular versiyon ölçümü.

$10^{\circ}$ 'nin üzerinde retroversiyon sıklığını rapor etmişlerdir. Femoral anteversiyonun $5^{\circ}$ 'nin altında olması, göreceli retroversiyon olarak kabul edilmektedir. Fabricant ve ark. ${ }^{[5]}$, FAS sendromu için cerrahi tedavi uyguladıkları 243 olguyu incelediklerinde, göreceli femoral retroversiyon olan olgularda elde edilen klinik iyileşmelerin, diğer versiyon derecelerine göre daha kötü olduğunu bulmuşlardır. Dy ve ark. ${ }^{[6]}$, femoral anteversiyon ile labrum veya kıkırdak hasarı arasında bir ilişki gösterememişlerdir. Aynı şekilde, FAS sendromu ve femoral anteversiyon arasında doğrudan bir ilişki saptanmamıştır. ${ }^{[7]}$ Displastik kalçalarda, asetabular anteversiyon artışı ile birlikte femoral anteversiyon da $\operatorname{artar}^{[8]}$

\section{Asetabular Versiyon}

Asetabular versiyon ölçümü, Dandachli ve ark. ${ }^{[9]}$ tarafından tarif edilen yöntemle, aksiyel kesitlerde yapılır. Burada, pelvis posterior duvarını birleştiren çizgiye, asetabulum posterior dudağı hizasında bir dikme çizilir. Bu dikme ile asetabulumun anterior ve posterior kenarlarını birleştiren çizgi arasındaki açı, asetabular versiyondur (Şekil 2). Normal asetabular versiyonun ne olduğu konusunda tartışmalar devam

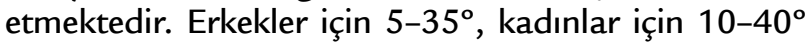
arasında ölçüm değerleri rapor edilmiştir. ${ }^{[10]} \mathrm{Bu}$ kadar farklı ölçümlerin nedeni ölçüm tekniği ile ilgili olabilir; ölçümün hangi kesitten yapıldığı ve pelvik tiltin göz önüne alınıp alınmadığı önemlidir. Dandachli ve ark. ${ }^{[9]}$, ortalama asetabular versiyon açısını, pelvik tilt düzeltildikten sonra $15,7^{\circ}$ bulmuşlardır. Daha kraniyal kesitlerde açı düşükken, ekvatora doğru açı büyümektedir. Heyworth ve ark. ${ }^{[3]}$, asetabular versiyon ölçümleri için, sagittal planda saat 1, 2 ve 3'e karşılık gelen aksiyel kesitlerin kullanımını önermektedirler. Bu kesitler, pincer lezyonu ve sıkışmanın en sık görüldüğü anatomik bölgeler olduğu için tercih edilmektedir. Herhangi bir kesitte versiyonun $15^{\circ}$ 'nin altında olması, asetabular retroversiyon olarak kabul edilir ve pincer lezyonunu destekler. Tannenbaum ve ark. ${ }^{[11]}$, asemptomatik bireylerde asetabular versiyon değerlerini cinsiyete göre ölçmüşlerdir. Ortalama global asetabular versiyon, erkeklerde $19,1^{\circ}$, kadınlarda ise $22,2^{\circ}$ bulunmuştur. Saat kadranlarına göre bakıldığında; saat 1 hizasında, erkeklerde $15,5^{\circ}$ ve kadınlarda $18,3^{\circ}$; saat 2 hizasında, erkeklerde $21,5^{\circ}$ ve kadınlarda $24^{\circ}$; saat 3 hizasında, erkeklerde $20,2^{\circ}$ ve kadınlarda $24,3^{\circ}$ olarak saptanmıştır. Gerçek retroversiyon, sadece saat 1 hizasında saptanabilmiştir.

Pelvik tiltin varlığı, asetabular versiyon ölçümünü etkiler. Ross ve ark. ${ }^{[12]}$, asetabular versiyonu kraniyal bölgede $3,3^{\circ}$ ölçerlerken, ekvator bölgesinde $16,2^{\circ}$ olarak bulmuşlardır. Pelvik tilt, bu ölçümleri önemli ölçüde etkiler; yazarlar, $10^{\circ}$ anterior tilt ile, asetabular retroversiyonun belirgin olarak arttığını bulmuşlardır. Aynı yazarlar, anterior pelvik tilt artışııın, direkt radyografilerde pozitif çaprazlama bulgusu, posterior duvar bulgusu ve belirgin iskial çıkıntı bulgusuna da yol açtığını göstermişlerdir. Bu nedenle, versiyon ölçümleri pelvik tilt için düzeltilerek yapılmalıdır. 


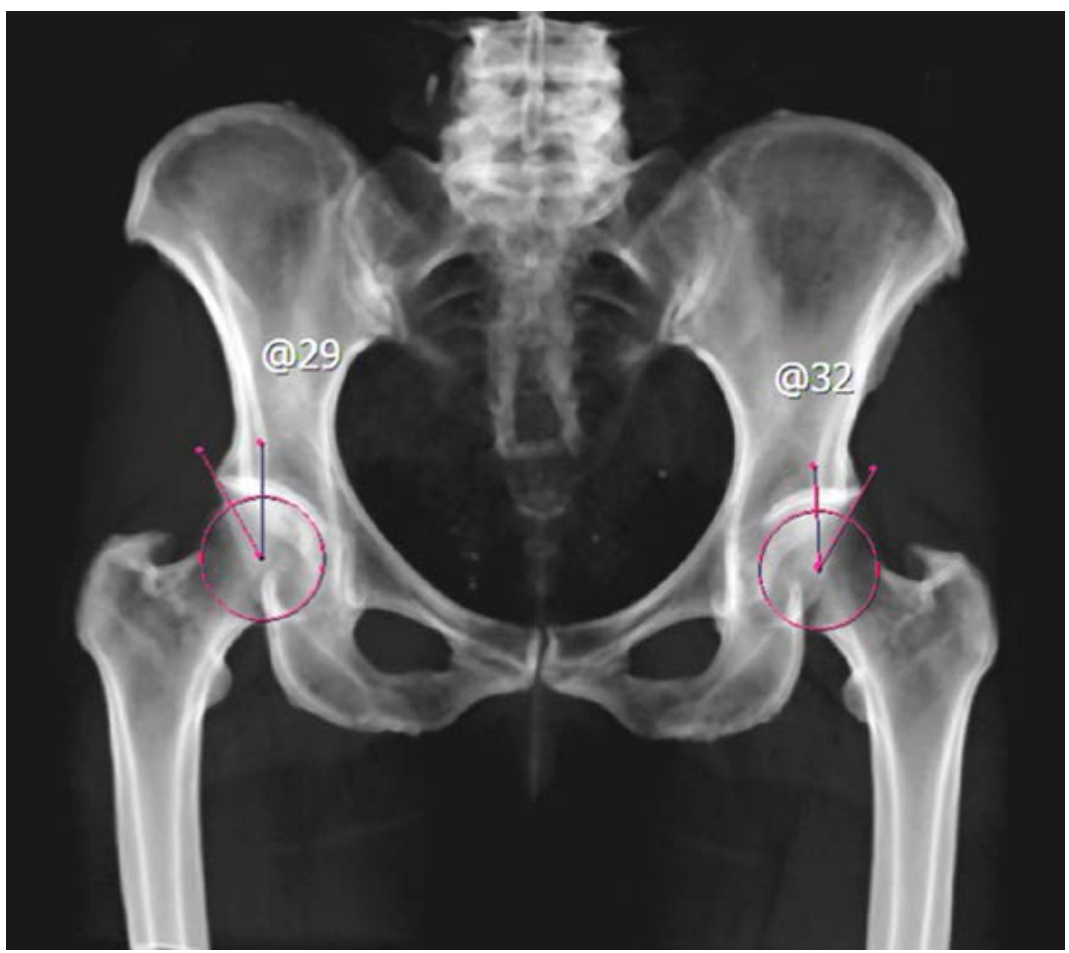

Şekil 3. Lateral merkez kenar açısının ölçümü.

\section{Lateral Merkez Kenar Açısı}

Asetabular örtünmenin ölçülmesinde kullanılan açılardan birisi de, lateral merkez-kenar (lateral center-edge angle) açısıdır. Femur başı merkezinden geçen dik çizgi ile, femur başı merkezi - asetabulum lateral duvarı arasına çizilen çizgi arasındaki açıdır (Şekil 3). Direkt radyografilerde yapılan ölçümlerde; $0-20^{\circ}$ arası displastik kalça, $20-40^{\circ}$ arası normal kalça, $40^{\circ}$ 'nin üzeri ise asetabular aşırı örtülme (coxa profunda) olarak kabul edilir. ${ }^{[13-15]}$ Tomografi kesitlerinde yapılan lateral merkez kenar açısı ölçümleri, ölçümün yapıldığı koronal kesitin nereden yapıldığına göre farklılıklar gösterir. Anteriordan alınan kesitlerde açı küçülürken, posteriora doğru olan kesitlerde büyür. Larson ${ }^{[13]}$, asemptomatik popülasyonda ortalama lateral CE açısını $31^{\circ}$ olarak bulmuştur. Werner ve ark. ${ }^{[15]}, 2452$ kalçanın incelemesinde, ortalama lateral merkez kenar açısını $33,6^{\circ}$ olarak rapor etmişlerdir.

BT ölçümlerinde, kalsifiye labrum veya os acetabuli varlığı ölçümleri zorlaştırıp, normalden daha yüksek açıların elde edilmesine yol açabilir. Baş merkezini saptarken, antero-lateral cam lezyonu göz ardı edilmeli ve başa en iyi uyan dairenin merkezi alınmalıdır. ${ }^{[16]}$

Tannast ve arkadaşları, cerrahi tedavi uyguladıkları hastaları incelediklerinde, lateral merkez kenar açısının $23^{\circ}$ 'nin altında olmasını displastik, $33^{\circ}$ 'nin üzerini ise aşırı örtünme olarak kabul etmişlerdir. ${ }^{[17]}$ Lateral merkez-kenar açısı ölçümleri pelvik tiltten etkilenmez; bu nedenle, BT kesitlerde düzeltme yapmaya gerek yoktur. ${ }^{[18]}$

\section{Alfa Açısı}

Başın sferisitesini değerlendirmek için yaygın olarak kullanılan alfa açısı, Nötzli tarafından MR kesitleri üzerinde tanımlanmıştır; ancak bu açı, hem direkt radyografilerde hem de $\mathrm{BT}$ kesitlerinde ölçülebilir. ${ }^{[19]}$ BT'de alfa açısının ölçümü, femoral başın en geniş olduğu aksiyel kesitten yapılmalıdır. Alfa açısının ölçümünde, femur boynunun uzun ekseni boyunca, femur başının merkezine bir çizgi çekilir. Subkondral kemiği en iyi örten bir daire çizilir. Femur başının bu dairenin dışına çıktığı noktadan, femur başı merkezine ikinci bir çizgi çekilir. Bu iki çizgi arasındaki açı, alfa açısıdır (Şekil 4). Nötzli, FAS sendromunda bu açıyı $70^{\circ}$ bulurken, kontrol grubunda $42^{\circ}$ olarak saptamıştır. Daha sonra, normal bireylerde alfa açısının değerleri konusunda onlarca çalışma yapılmıştır. Irk ve cinsiyet farklılıklarının olduğu gösterilmiştir. Asya toplumlarında alfa açısı daha düşüktür ve asemptomatik bireylerde, Batı toplumu için patolojik kabul edilen $50^{\circ}$ 'nin üzerine çıkması çok nadirdir. ${ }^{[20,21]}$ Genel olarak kabul 


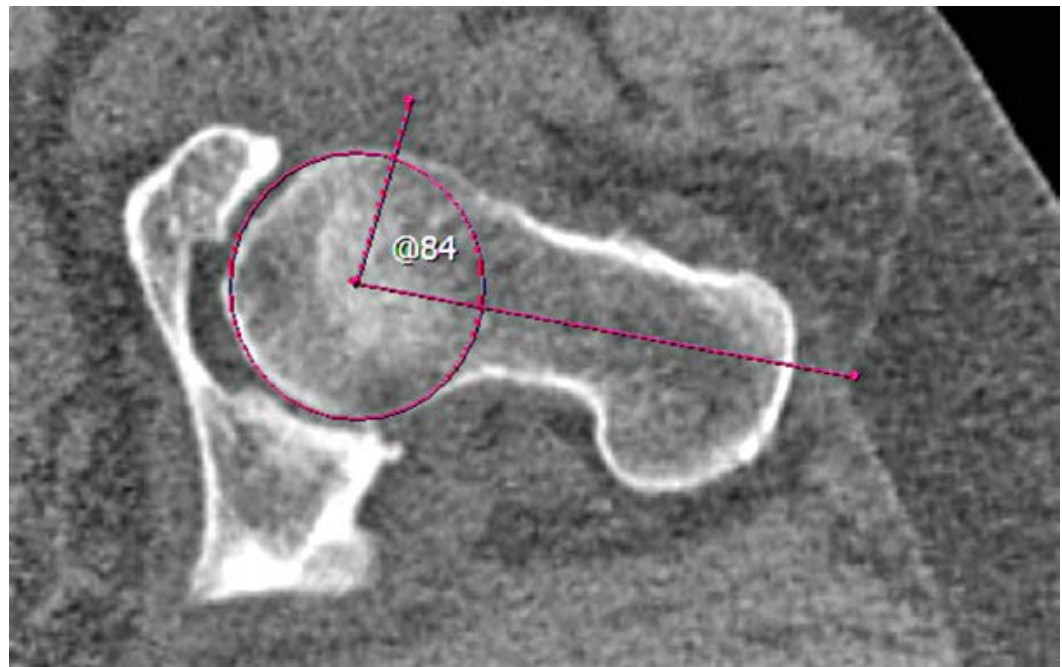

Şekil 4. Alfa açısının ölçümü.

edilen görüş, $60^{\circ}$ 'nin üzerindeki alfa açısının patolojik olduğudur. Ancak, tek başına alfa açısının yüksek olması FAS tanısı için yeterli değildir.

BT ile ölçülen alfa açısı, direkt radyografilere göre farklı olabilir. Cadet ve ark. ${ }^{[22]}$, direkt radyografilerde $61,1^{\circ}$ olarak ölçülen alfa açısını, 3B BT ile $55,4^{\circ}$ olarak bulmuşlardır.

\section{Beta Açısı}

Beaule ve ark. ${ }^{[23]}$ tarafindan tanımlanan bu açı, esas olarak, alfa açısının posteriordan ölçümüdür; femur boynunun posterior konkavitesinin ölçümünü hedefler (Şekil 5). Yazarlar, semptomatik grupta beta açısını $40,2^{\circ}$ bulurken, asemptomatik grupta $43,8^{\circ}$ olarak bulmuşlardır. Alfa/beta oranın 1,25'in üzerinde olması, FAS için \%100 özgün bulunmuştur.

\section{Baş-Boyun Ofset Ölçümü}

Aksiyel kesitlerde yapılan ölçümlerde, femur boynu anterioru boyunca çizilen çizgi ile, femur başının en geniş anterior noktasından çekilen paralel çizgi arasındaki mesafe ölçümüdür (Şekil 6). ${ }^{[24]}$ Bu mesafenin 9 mm'nin altında olması, ofset azalması yani cam tipi FAS lezyonuna işaret eder. Kişisel farklılıkları gidermek ve ölçümü standardize etmek amacıyla, bu ölçüm başın çapına bölünerek ofset oranı elde edilir. Bu oran 0,21 $\pm 0,03$
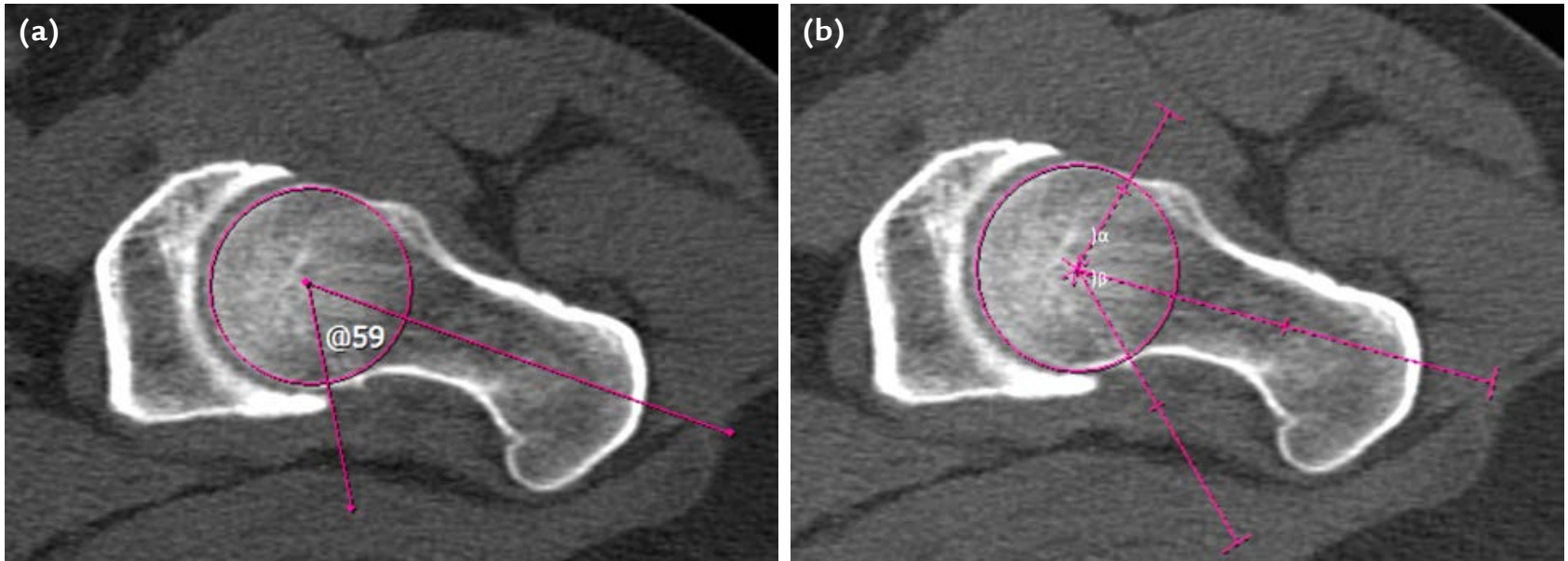

Şekil 5. a, b. Beta açısının ölçümü (a). Aynı kesitte alfa ve beta açılarının ölçülmesi (b). 


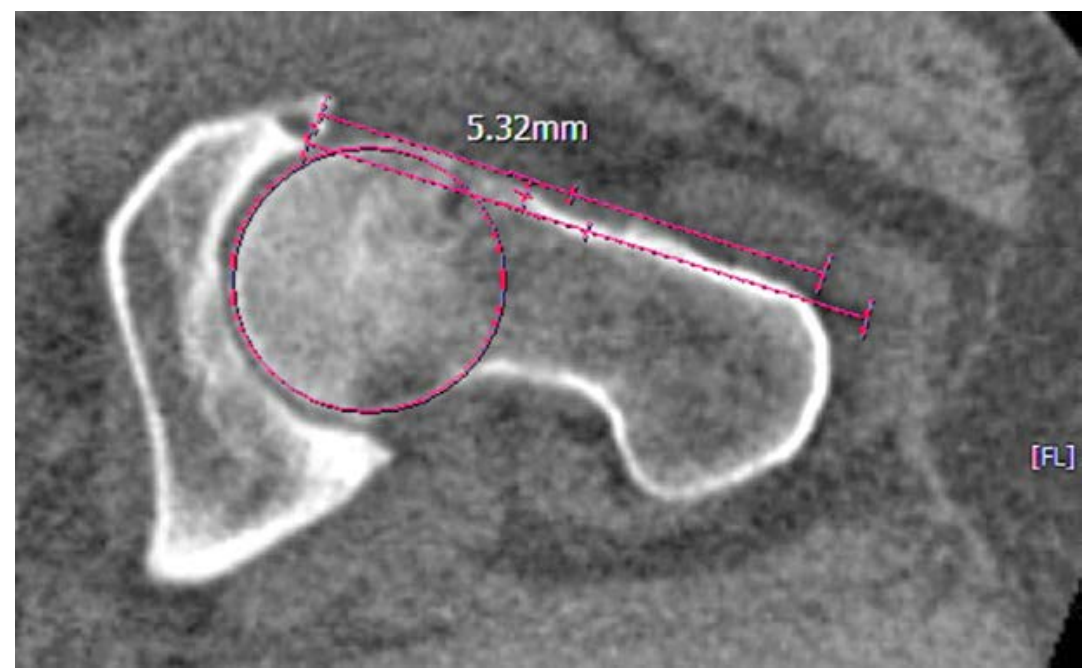

Şekil 6. Baş-boyun ofset miktarının ölçümü.

ise normaldir, $0,13 \pm 0,05$ ise cam lezyonuna işaret eder. Daha sonraki çalışmalarda da, anterior ofsetin azalmasının cam lezyonunu göstermede etkili bir yöntem olduğu doğrulanmıştır. Bazı çalışmalarda 7 bazılarında 5 mm'nin altında ofset patolojik kabul edilmiştir. ${ }^{[25]}$

Nemtala ve ark. ${ }^{[26]}$, daha sonra, anterior ofset $(\mathrm{AO})$ / posterior ofset (PO) oranını ölçmüşler ve bunun antropometrik özelliklerden etkilenmediğini bulmuşlardır. Bu oran, cam lezyonu olanlarda $0,56 \pm 0,1$, asemptomatik olgularda ise $0,9 \pm 0,2$ olarak saptanmıştır.

\section{Omega Alanı}

Normal bireylerde de bazı FAS parametrelerinin pozitif olabileceği, femur ve asetabulumdaki farklı parametrelerin birbirlerini etkilediği bulgusundan hareketle, birden fazla ölçümün kombine edilerek kullanıldığı ölçümler gündeme gelmiştir. Bunlardan birisi, Bouma ve ark. ${ }^{[27]}$ tarafından tanımlanan omega alanıdır. Burada, 3B BT görüntülerinden elde edilen beş ölçüm (alfa açısı, merkez-kenar açısı, asetabular versiyon, femoral versiyon ve femur şaft-boyun açıları) kombine edilerek, kalçanın sıkışma olmadan yapabileceği hareket alanı hesaplanır. Yazarlar, omega alanı ölçümünün, asemptomatik ancak alfa açısının $55^{\circ}$ 'nin üzerinde olduğu bireylerle semptomatik cam tipi sıkışma olan hastaları ayırt edebildiğini göstermişlerdir. Bu ölçüm aynı zamanda, cerraha femur veya asetabulumun hangi kesimlerine müdahale etmesi gerektiği konusunda bilgiler de verir. Rego ve ark. ${ }^{[28]}$, omega alanı ölçümleri ile daha doğru ve yeterli cam rezeksiyonu planlanabildiğini göstermiş̧lerdir.

\section{ASEMPTOMATIK BIREYLERDE FAS BULGULARI}

Literatürdeki birçok çalışmada, asemptomatik bireylerde FAS morfolojisi olabileceği gösterilmiştir. Ergen ve ark. ${ }^{[29]}$, başka nedenlerle BT çekilen asemptomatik bireylerde; anormal alfa açısını \%20,2, azalmış başboyun ofsetini \%26,8, artmış merkez-kenar açısını $\% 25,8$ ve azalmış asetabular versiyon açısını \%10,2 olguda bulmuşlardır. Asemptomatik bireylerde, özellikle erkeklerde $60^{\circ}$ 'nin üzerinde alfa açısı prevalansı oldukça yüksektir. Hack ve ark.. ${ }^{[30]}, 200$ asemptomatik gönüllüde yaptıkları çalışmada, yüksek alfa açısı ve cam morfolojisini \%14 olarak rapor etmişler, erkeklerde bu oranı daha yüksek bulmuşlardır. Sporcularda bu oranın daha yüksek olduğu gösterilmiştir. Amerikan futbolu oyuncularında yapılan bir çalışmada, kalçaların \%52'sinde pincer bulgusu, \%22'sinde cam bulgusu olduğu gösterilmiştir. ${ }^{[31]}$ Hastaların \%95'inde, en az bir FAS bulgusu vardır. Bu çalışmada, hastaların \%72'sinde anormal alfa açısı, \%64'ünde azalmış baş-boyun ofseti, \%61'inde pozitif çaprazlama bulgusu, \%16'sında azalmış asetabular indeks ve \%7'sinde artmış lateral merkez kenar açısı olduğu bildirilmiştir. Asemptomatik 473 bireyin kalça BT'lerinin değerlendirildiği başka bir çalışmada, eklemlerin \%40'ında en az bir FAS radyolojik kriteri olduğu bulunmuştur. ${ }^{[32]}$ Bu çalışmada, pozitif FAS bulgusu kriterleri; alfa açısının $55^{\circ}$ 'den büyük olması, baş-boyun ofsetinin $8 \mathrm{~mm}$ den az olması, asetabular versiyon açısının $15^{\circ}$ 'nin altında olması, lateral merkez kenar açısının $40^{\circ}$ 'nin üzerinde olması olarak kabul edilmiştir. Erkeklerin \%43,2'sinde, kadınların ise $\% 35,4$ 'ünde en az bir kriter pozitif olarak bulunmuştur. 

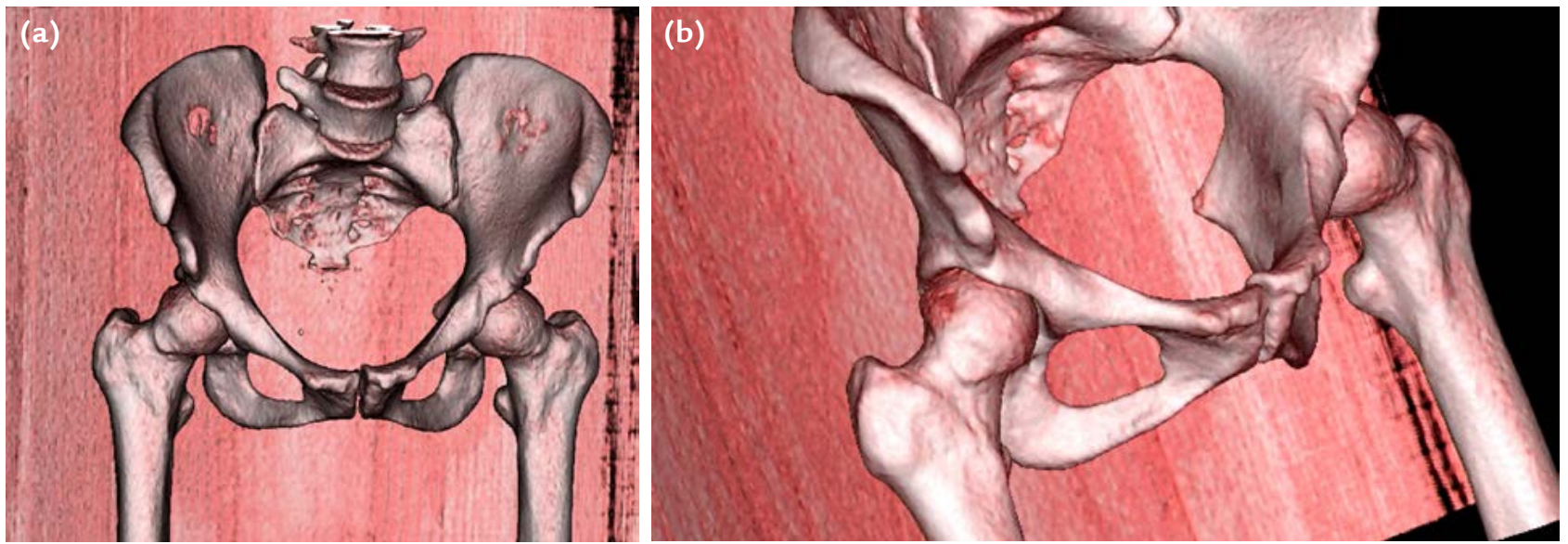

Şekil 7. a, b. 3B BT ile değişik açılardan cam lezyonunun gösterilmesi.

Bütün bu çalışmalar göz önüne alındığında, FAS morfolojisinin toplumda hiç de azımsanmayacak oranda görülebildiğinin altı çizilmelidir. FAS sendromu tanısı koyabilmek için, çok dikkatli bir klinik muayene ile semptomların kalça ekleminden kaynaklandığı doğrulanmalı ve birden fazla radyolojik ölçümün pozitifliği aranmalıdır. Şüphede kalınan durumlarda, bir süre konservatif izlem ile gidilerek, cerrahiye karar vermeden önce FAS tanısından emin olunmalıdır. Literatürde, FAS morfolojisi olan asemptomatik bireylerde profilaktik cerrahiyi destekleyen bir çalışma yoktur.

\section{FAS MORFOLOJISININ DEĞERLENDIRILMESI}

İnce kesitlerin alınmasından sonra, yazılımlar sayesinde kalça ekleminin 3B kemik morfolojisinin saptanması, hem FAS tanısında hem de cerrahi tedavinin planlanmasında önemli ipuçları verir. Cam lezyonunun yeri ve boyutları ayrıntılı olarak görülebilir ve cerrah, rezeksiyon miktarı konusunda 3B bilgi edinir; pincer lezyonunun yerleşimi değişik açılardan değerlendirilir; os acetabuli varsa görüntülenebilir. Ayrıca, 3B BT ameliyat sonrası dönemde çekildiğinde, osteokondroplasti ile yeterli rezeksiyon yapılıp yapılmadığının da değerlendirilmesine katkı sağlar.

\section{Cam Morfolojisi}

Cam lezyonunun yerleşimi ve boyutları, en iyi 3B BT kesitlerinin değişik açılardan incelenmesi ile saptanabilir (Şekil 7). Bütün cam lezyonları aynı değildir. Mellado ve ark. ${ }^{[33]}$, BT görüntülerinde cam tipi lezyonları üç ana grupta toplamışlardır. Bunlar:

1. Epifizyel skar bölgesinde fokal çıkıntı, ancak ofset kaybı yok (Şekil 8).
2. Baş-boyun ofset kaybı var, belirgin çıkıntı yok (Şekil 9).

3. Anterior konveksite, diffüz kabarıklık ve epifizyel retroversiyon. Bu tip, ön arka grafide superior ofset kaybı, konveks görünüm ve tabanca kabzası (pistol-grip) deformitesi şeklinde karşımıza çıkar.

\section{Asetabular Morfoloji}

Pincer lezyonunun BT ile değerlendirilmesi daha zordur. Direkt grafilerde görülen çaprazlama bulgusunun, BT karşılığı yoktur. Bu nedenle, fokal asetabular retroversiyon farklı BT teknikleri ile değerlendirilmeye çalışıIır. Bunlardan biri, asetabulumu saat kadranlarına böldükten sonra, anteriorda saat 1, 2 ve 3 hizasındaki aksiyel kesitlerde asetabular versiyonun değerlendirilmesidir. ${ }^{[13]}$ Distale doğru giderken versiyon değerinde ciddi bir artış olması, pincer lezyonu lehine değerlendirilebilir. Ancak, asemptomatik olguların bir kısmında da bu versiyon değişimi görülebilir. Larson ve ark. ${ }^{[13]}$, lateral merkez kenar açısı $20^{\circ}$ 'nin altı ve $40^{\circ}$ 'ı üzeri olan hastaları dışladıktan sonra inceledikleri 474 asemptomatik kalçanın BT'lerinde, saat 1 hizasında erkeklerin \%19'u, kadınların ise \%11'inde asetabular retroversiyon saptamışlardır; bu oran, saat 2 hizasında \%1-2'lere inmiş, saat 3 hizasında sıfır olmuştur. Bu da bize, asemptomatik erkeklerin neredeyse beşte birinde çaprazlama bulgusunun pozitif olabileceğini göstermektedir.

Femur başının örtünme miktarı da BT ile hesaplanabilir. Dandachli ve ark. ${ }^{[9]}$, normal bireylerde örtünmeyi \%73 (\%66-81), displastik kalçalı bireylerde ise \%51 (\%38-64) olarak saptamışlardır. Normal bireylerde, posterior örtünme \%35-43 arası, anterior örtünme \%30-38 arasıdır. 


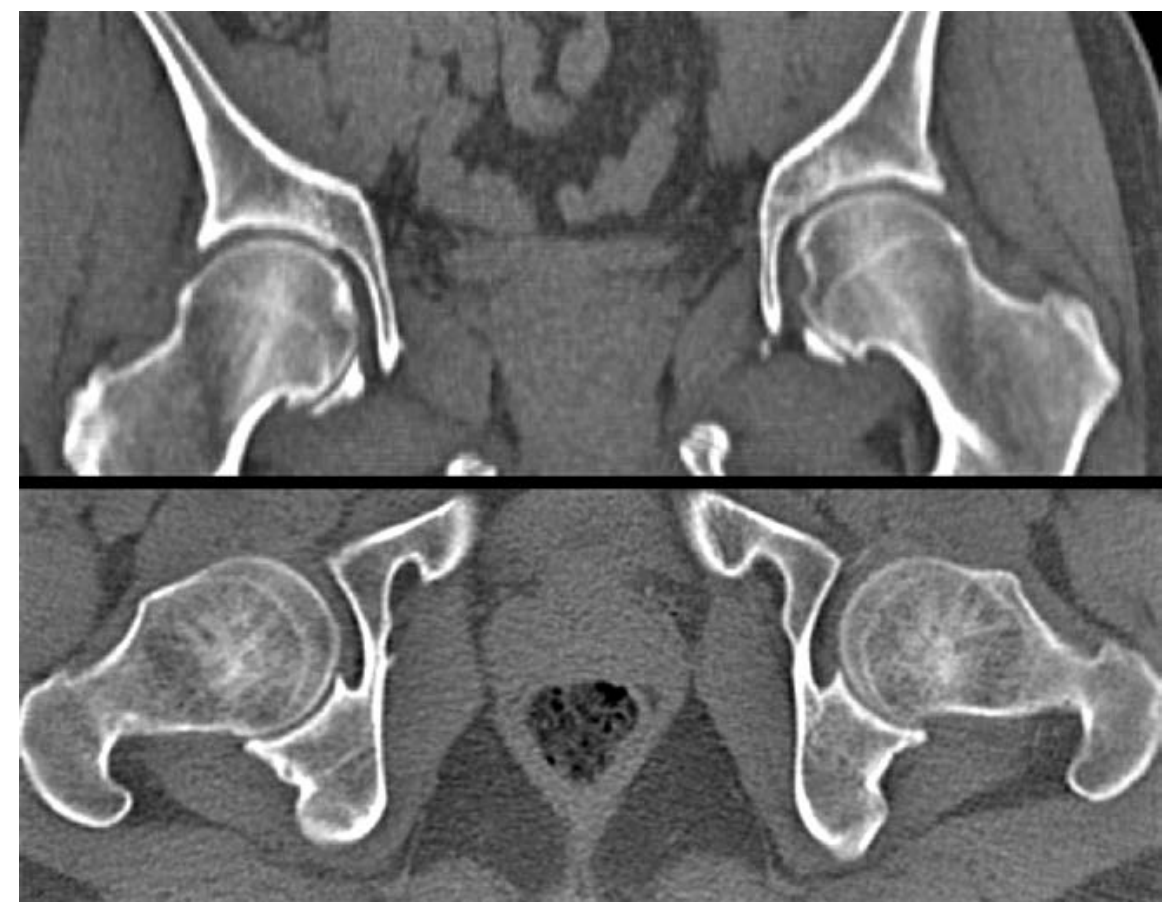

Şekil 8. Çıkıntının belirgin olduğu cam deformitesi.

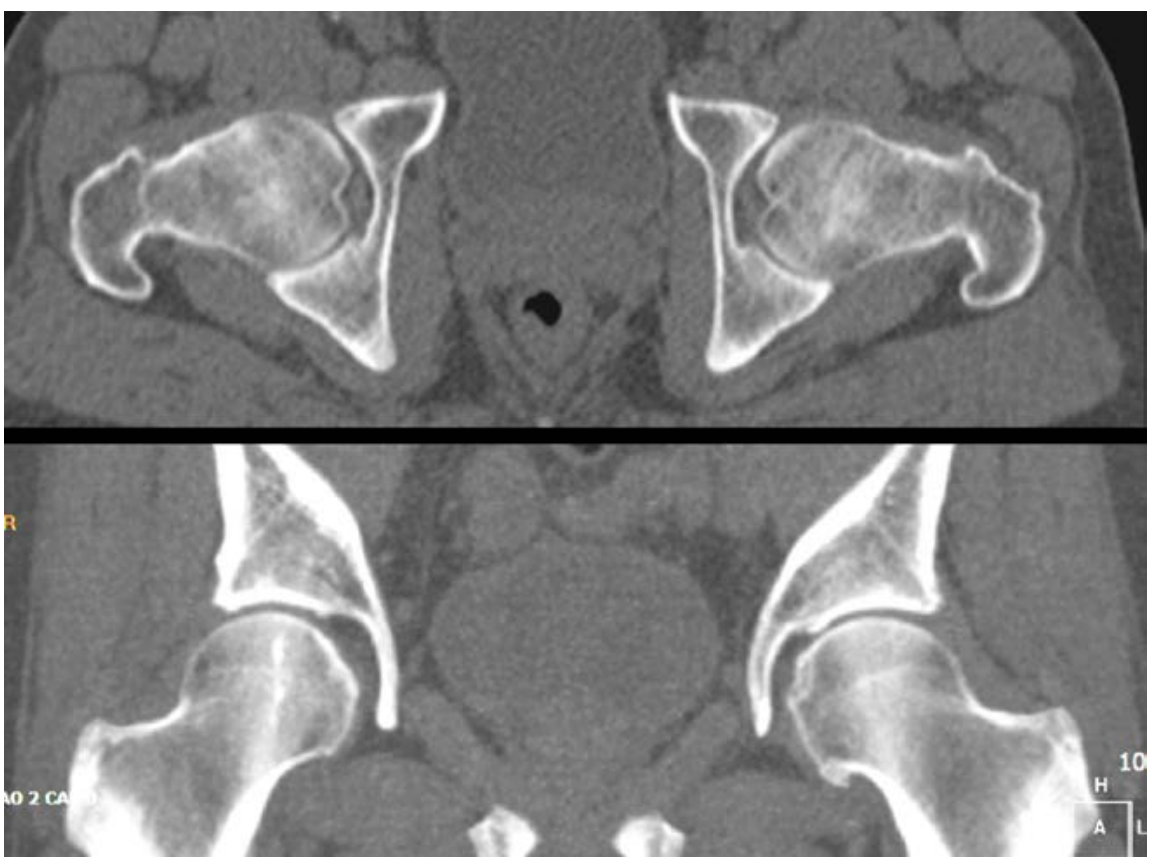

Şekil 9. Ofset kaybının belirgin olduğu cam deformitesi.

Aynı cam lezyonunda olduğu gibi, 3B BT ile pincer lezyonunun yerleşimi ve boyutları ayrıntılı olarak görüntülenebilir (Şekil 10). Asetabular labrumun altında görülen subkondral kistler ve labrum ossifikasyonları BT ile gösterilebilir (Şekil 11).

\section{Femur Boynunda Kistler}

Femur baş-boyun bileşkesinin antero-superiorunda görülen kistler de, FAS sendromunun ikincil belirtilerindendir (Şekil 12). Birden fazla olabilen bu kistler, aynı zamanda, cam lezyonunun yerini ya da 


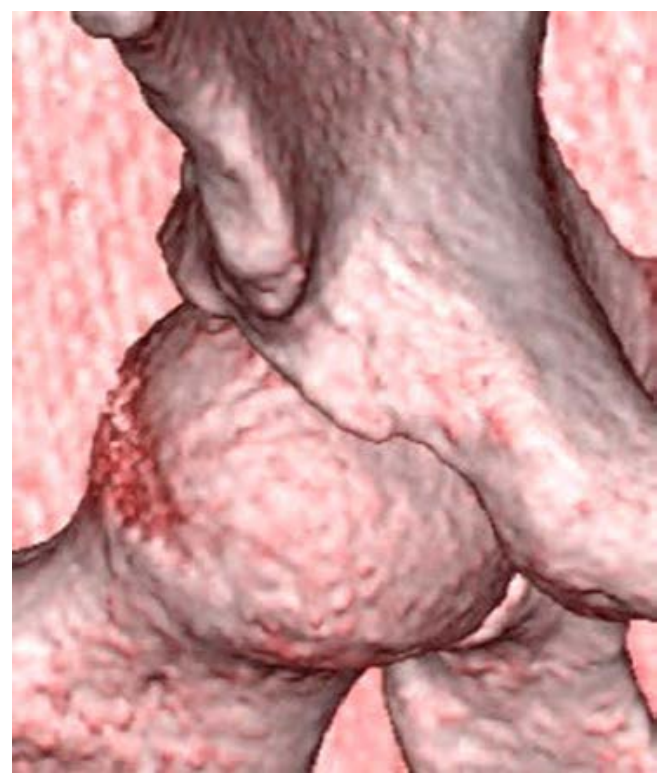

Şekil 10. 3B BT ile pincer lezyonunun gösterilmesi.
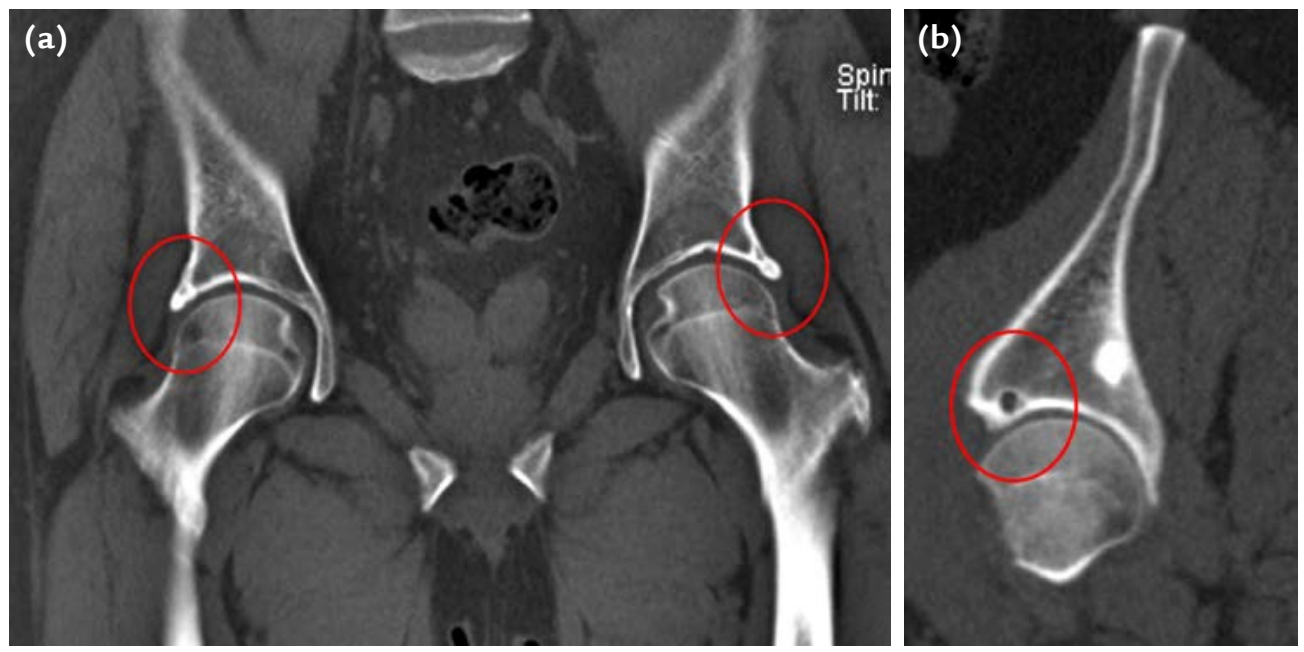

Şekil 11. a, b. BT'de bilateral labrum ossifikasyonları (a). Sublabral kistin görünümü (b).

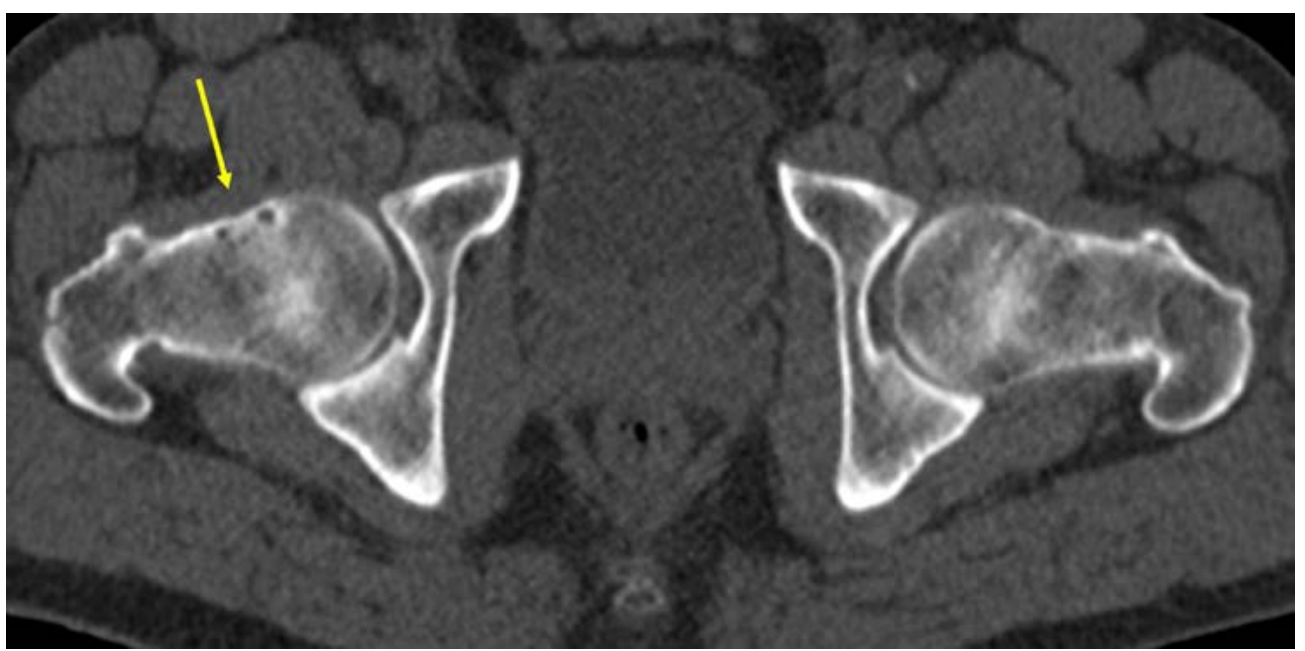

Şekil 12. Aksiyel kesitte femur boynunda sıkışma bölgesinde subkondral kistler. 

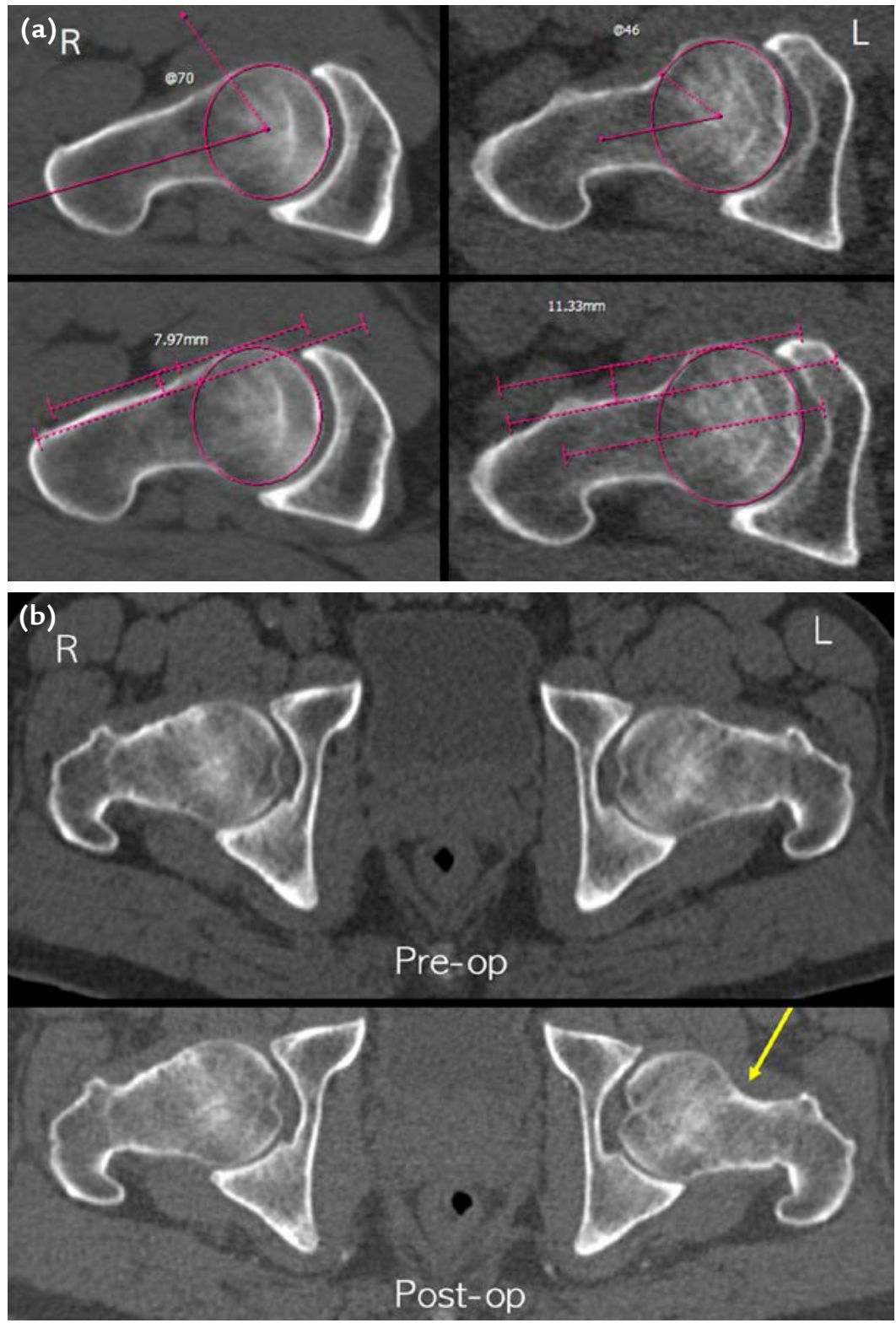

Şekil 13. a, b. Sol kalçası ameliyat edilmiş, sağ kalçası için cerrahi planlanan hastanın BT görüntüleri: sağ kalçada FAS bulguları var, solda ölçümler normale gelmiş (a); ameliyat öncesi BT ile karşılaştırmada sol tarafta yeterli cam rezeksiyonunun yapıldığı görülmekte (sarı ok) (b).

pincer lezyonunun femur boynu ile temas ettiği yeri belirler. Çoğu kist, cam lezyonuna uygulanan osteokondroplasti sırasında görünür hale gelir; kırık riski oluşturacak kadar büyük olanlar greftlenebilir; ancak, çoğu zaman başkaca bir işlem yapılmasına gerek yoktur. Leunig ve ark. ${ }^{[34]}, 141$ olguluk bir seride, hastaların \%18'inde kistlerle karşılaşmışlar, yeterli cam rezeksiyonu sonrası çoğu kistin de çıkartıldığını saptamışlar ve hiçbir olguda femur boynunda kırığa rastlamamışlardır.

\section{AMELIYAT SONRASI BT DEĞERLENDIRMESi}

FAS cerrahisi sonrası rutin BT değerlendirmesi gereksizdir. Ancak, yakınmaları devam eden veya revizyon cerrahisi planlanan hastalarda, tedavi planlaması açısından BT değerli bilgiler verir (Şekil 13). Yakın zamanda yayımlanan iki sistematik derlemede, FAS cerrahisi sonrası en önemli revizyon nedeninin yetersiz kemik rezeksiyonu olduğu gösterilmiştir. ${ }^{[35,36]} 3 \mathrm{~B} \mathrm{BT}$, bu durumlarda çok değerli bulgular verecektir. 


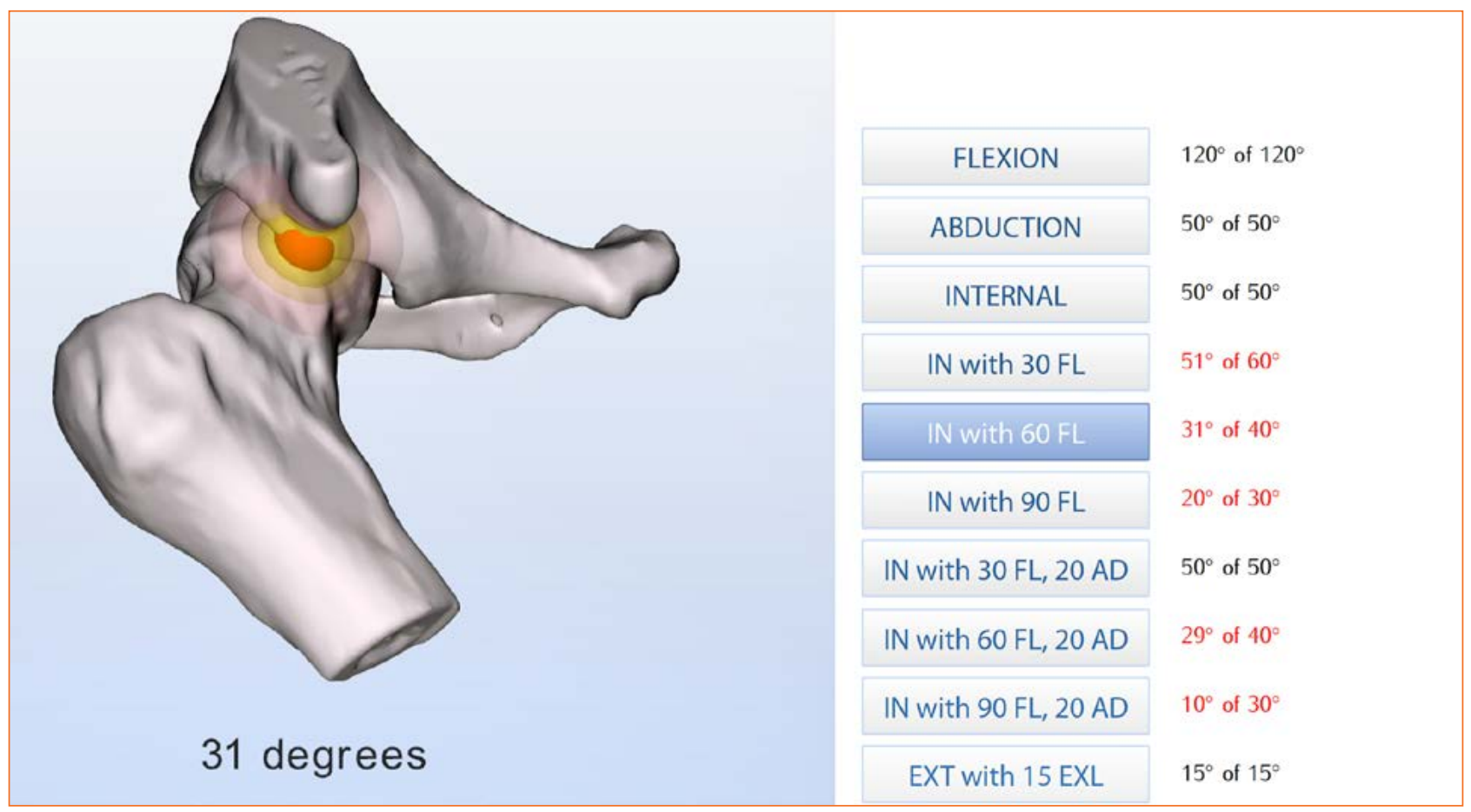

Şekil 14. 3B Dinamik değerlendirmede, $60^{\circ}$ fleksiyon ve $15^{\circ}$ iç rotasyonda sıkışmanın olduğu bölge görülmekte (Clinical Graphics programı).

\section{FAS'TA DINAMIK DiJiTAL DEĞERLENDIRME}

FAS tanısı için kullanılan statik radyolojik parametrelerin normal popülasyonda da belli oranda pozitif olabilmesi, FAS tanısını zorlaştırmaktadır. Özellikle, klinik muayene bulgularının şüpheli olduğu durumlarda ya da silik radyolojik bulguların varlığında kullanılabilecek yöntemlerden birisi, dijital dinamik değerlendirmedir. Bu ölçümde, hastaların ince kesit BT veya $M R$ görüntüleri, özel bilgisayar yazılımları sayesinde dijitalize edilerek, femur ve pelvisin 3B modelleri oluşturulur. Daha sonra, bu modeller üzerinde hem statik FAS parametreleri ölçülebilir hem de dinamik olarak hangi hareket açıklığı ve açılarda femoroasetabular sıkışmanın ortaya çıktığı gösterilebilir (Şekil 14). Bütün ölçümler femur boynu ve astetabulumun farklı noktalarından tekrarlandığı için, deformitenin en fazla hangi bölgede olduğu çok daha kolay saptanabilir (Şekil 15). Dijital modeller üzerinde, pelvis veya femurda hangi bölgelerin ne kadar rezeke edilmesi gerektiğinin haritaları da çıkartılarak, cerrahi planlama hatta sanal cerrahi yapılabilir (Şekil 16). ${ }^{[37]}$ Sadece FAS değil, aynı zamanda subspine ve iskiofemoral sıkışma durumlarında da bu değerlendirmelerden yararlanılabilir. Röling ve ark. ${ }^{[38]}$, dijital dinamik değerlendirme sırasındaki hareket ölçümlerinin $1,9^{\circ}$ hassasiyetle doğru olduğunu, kadavra çalışmalarında göstermişlerdir.
Halen klinik kullanımda olan iki sistem ile ilgili başarılı sonuçlar bildirilmiştir. Bunlardan biri Clinical Graphics (Delft, Hollanda), diğeri MSC visual Nastran 4D (MSC Santa Ana, CA, USA) yazılımlarıdır. Ayrıca, ticari olmayan ve araştırma amacıyla geliştirilmiş başka yazılımlar da cerraha 3B dinamik değerlendirme imkanı sunmaktadır. ${ }^{[39,40]}$

\section{BT ARTROGRAFI}

FAS sendromuna eşlik eden eklem içi patolojilerin tanısı için, standart BT incelemeleri yetersizdir. Bu hastalarda eşlik edebilecek kıkırdak ve labrum hasarını göstermek amacıyla, BT artrografi uygulamaları yapılmıştır. Eklem içi gadolinyum enjeksiyonu gerektirmesi nedeniyle, invaziv bir yöntemdir. Literatürde Artro-BT ile MR-artrografiyi karşılaştıran çalışmalarda, labrum lezyonlarında benzer doğruluk oranları bulunurken, kıkırdak hasarını göstermede MRartrografi biraz daha üstün bulunmuştur. ${ }^{[41,42]} \mathrm{Her}$ iki yöntemle de \%75-90 civarında duyarlılık ve özgüllük oranları rapor edilmiştir. BT-artrografinin duyarlılığını yükseltmek ve kıkırdak lezyonlarının tanı yüzdesini arttırmak amacıyla, traksiyon altında BT-artrografi uygulaması önerilmiştir. ${ }^{[43]}$

Cam tipi FAS'ta, kondrolabral bileşkedeki kıkırdak örtüsünün devamlılığında bozulma olmadan altındaki 


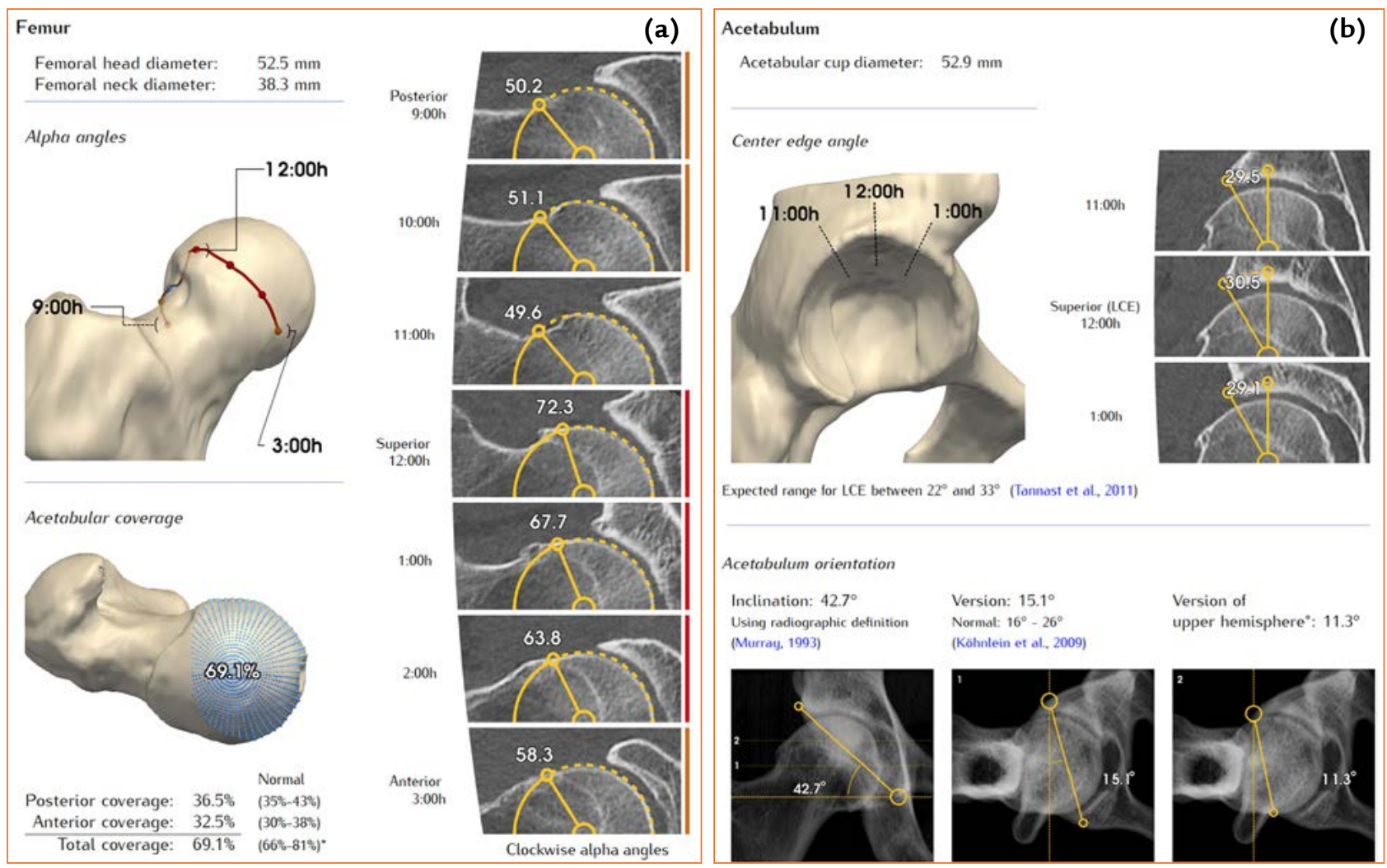

Şekil 15. a, b. Şekil 14'teki olguda BT ölçümleri: femurda saat kadranlarına göre alfa açıları ve başın örtünme miktarının ölçülmesi (a); asetabulumda saat kadranlarına göre lateral merkez-kenar açıları ve asetabular yönelimin ölçülmesi (b).

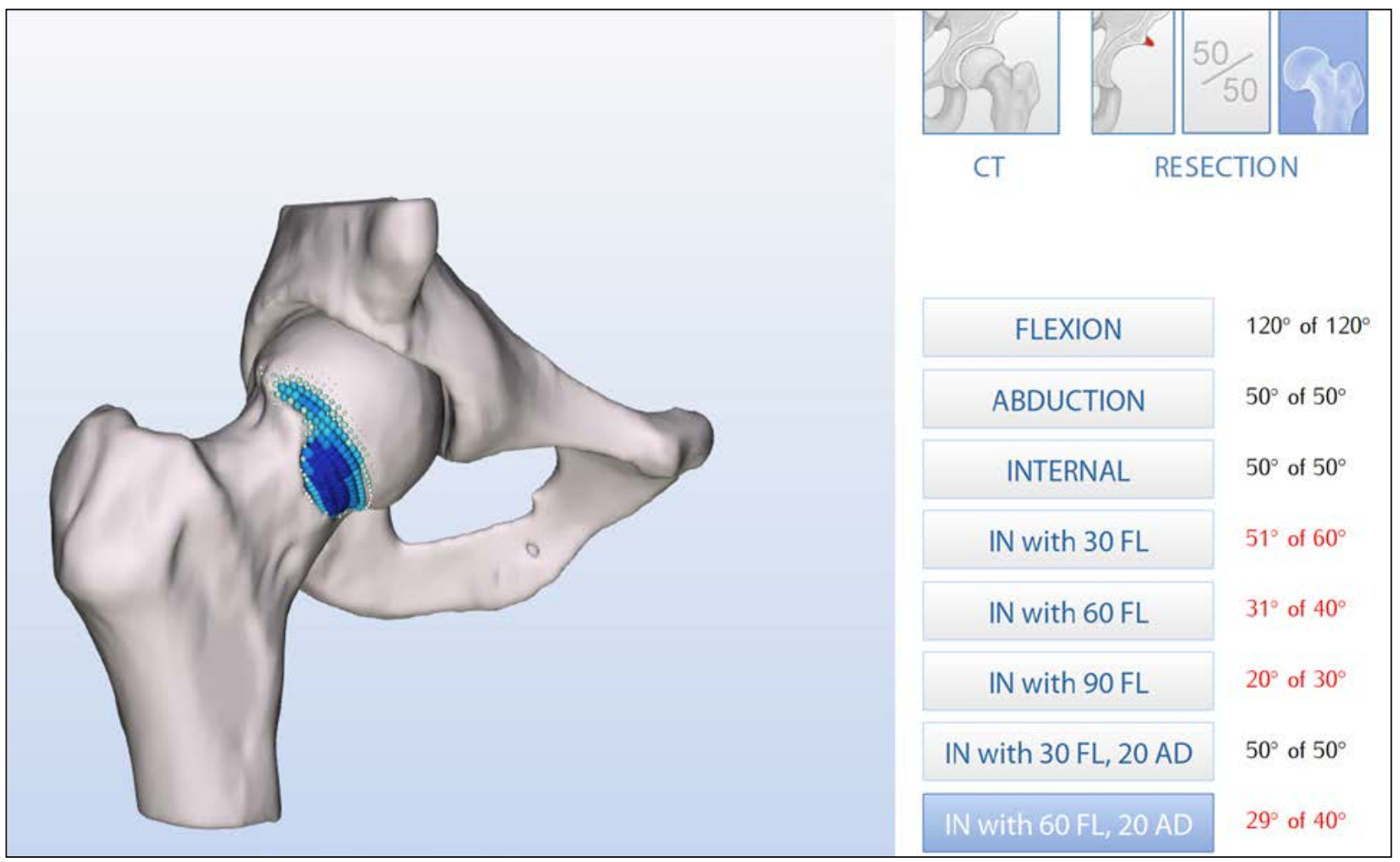

Şekil 16. Şekil 14'teki olguda rezeke edilmesi gereken cam deformitesinin haritalanması. 


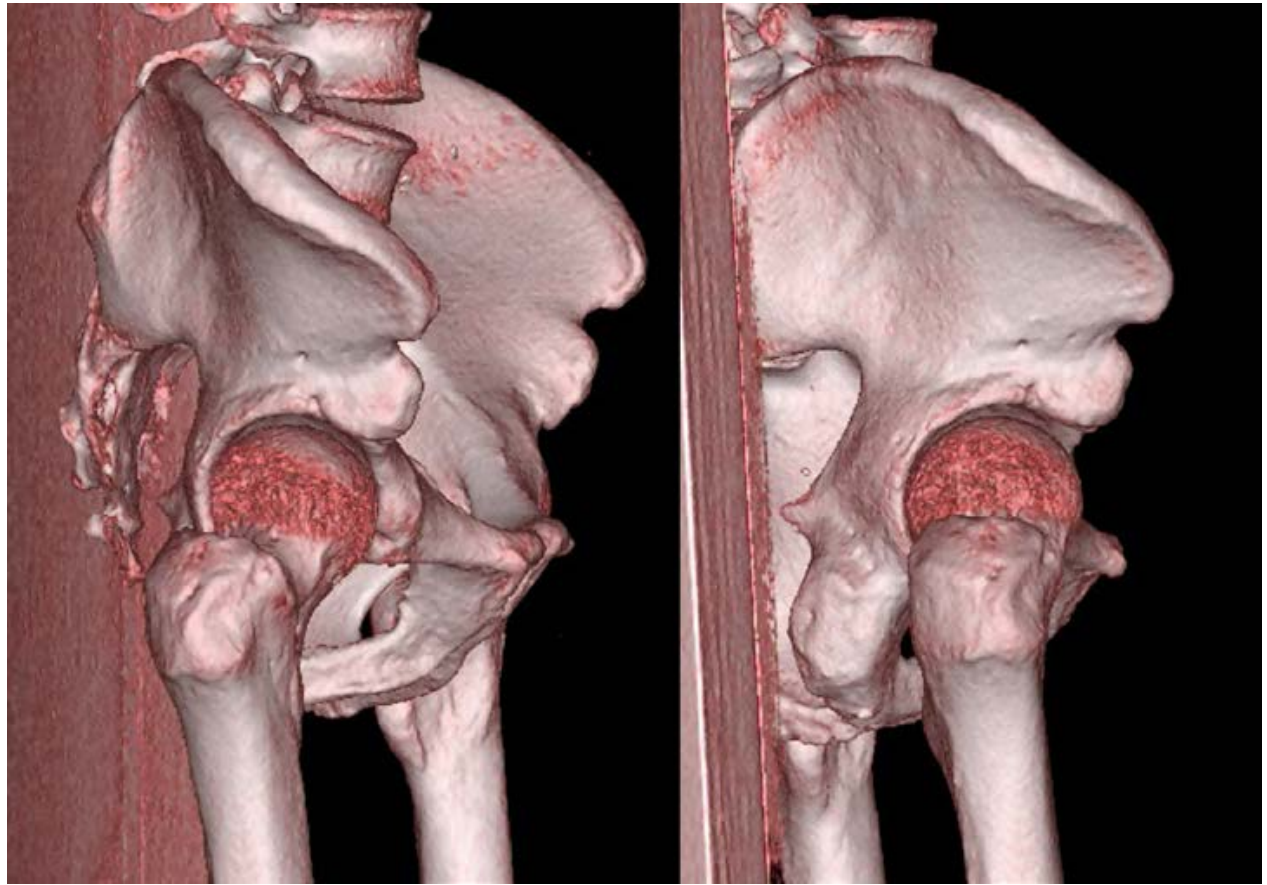

Şekil 17. 3B BT ile Tip III Aiis morfolojisinin ortaya konması.

kemikten ayrılması, yani halı belirtisi, güncel görüntüleme yöntemleri ile tespit edilemez. Bu lezyon, ancak artroskopi sırasında, kıkırdağın palpasyonu ile ortaya konabilir. Smith ve ark. ${ }^{[44]}, 18$ çalışmanın meta-analizinde, MR, Artro-MR ve Artro-BT'nin kalça kıkırdak lezyonlarındaki etkinliğini karşılaştırmışlardır. Artro$M R$, standart MR'den üstün bulunmuş, Artro-BT için yeterli veri olmadığı gözlenmiştir. Bu çalışmada, kıkırdak lezyonlarını tanısında altın standardın hala artroskopi olduğu doğrulanmıştır.

\section{ANTERIOR INFERIOR ILIAK SPINA SIKIŞMASI}

Anterior inferior iliak spina (Aiis) sıkışması, ekstraartiküler FAS nedenlerinden birisidir. Gelişimsel, posttravmatik ya da pelvik osteotomi sonrası, Aiis asetabulum tavanı hizasına gelir veya distaline inerse, FAS sendromuna yol açabilir. Artroskopi sırasında, tipik olarak bu bölgede, labrumda hemoraji ve yırtıklar veya kondro-labral ayrılmalar ortaya çıkar. ${ }^{[45]}$ Hetsroni ve arkadaşları, ${ }^{[66]}$ üç tip Aiis morfolojisi tanımlamışlardır:

Tip 1: AilS ile asetabulum kenarı arasında düz bir ilium yüzeyi vardır.

Tip II: Aiis asetabulum kenarına kadar uzanır.

Tip III: Aiis asetabulum kenarının distaline doğru devam eder.

Yazarlar, Tip II ve III Aiis morfolojisi olan hastalarda, kalça fleksiyon ve iç rotasyonunun kısıtlandığını göstermişlerdir.
Aiis sıkışmasını en iyi gösteren görüntüleme yöntemi 3B BT'dir. Pelvis değişik açılarda döndürülerek, Aiis ve asetabulum üst kenarının ilişkisi ortaya konabilir (Şekil 17).

Sanverdi ve ark. ${ }^{[47]}$, normal bireylerde Aiis mesafesini 3B BT ile ölçmüşler; kadınlarda $13,61 \pm 2,85 \mathrm{~mm}$, erkeklerde $17,22 \pm 3,34 \mathrm{~mm}$ ve ortalama $15,77 \pm 3,73$ $\mathrm{mm}$ bildirmişlerdir (Şekil 18).

\section{iSIKIO-FEMORAL SIKIŞMA}

Yeni tanımlanan ekstra-artiküler kalça sıkışma sendromlarından biri de, iskio-femoral sıkışma sendromudur. Trokanter minör ile iskium arasında kuadratus femoris kasının sıkışması sonrası, derin posterior kalça ağrısı ile karakterize bir hastalıktır. Fizik inceleme sırasında, kalça ekstansiyon, adduksiyon ve dış rotasyonu ile ağrı ortaya çıkar. ${ }^{[48]}$ i̇skium ile trokanter minör arasındaki mesafenin, konjenital veya iskial avülziyon kırıklarının kötü kaynaması sonrası, daralması olarak tanımlanır. Genellikle bilateraldir ve kadınlarda daha sık görülür. Asıl tanısı MR'de, aksiyel kesitlerde, kuadratus femoris kasında ödem ve parsiyel yırtık ile birlikte iskio-femoral mesafenin $12 \mathrm{~mm}$ altında olması ile konur (Şekil 19). ${ }^{[49]}$ Ancak, aksiyel BT kesitlerinde bu mesafenin daralmış olması tanıya yardımcı olabilir. Bu sıkışma, BT görüntülerinden elde edilen dinamik 3B değerlendirmeler ile doğrulanabilir (Şekil 20). 


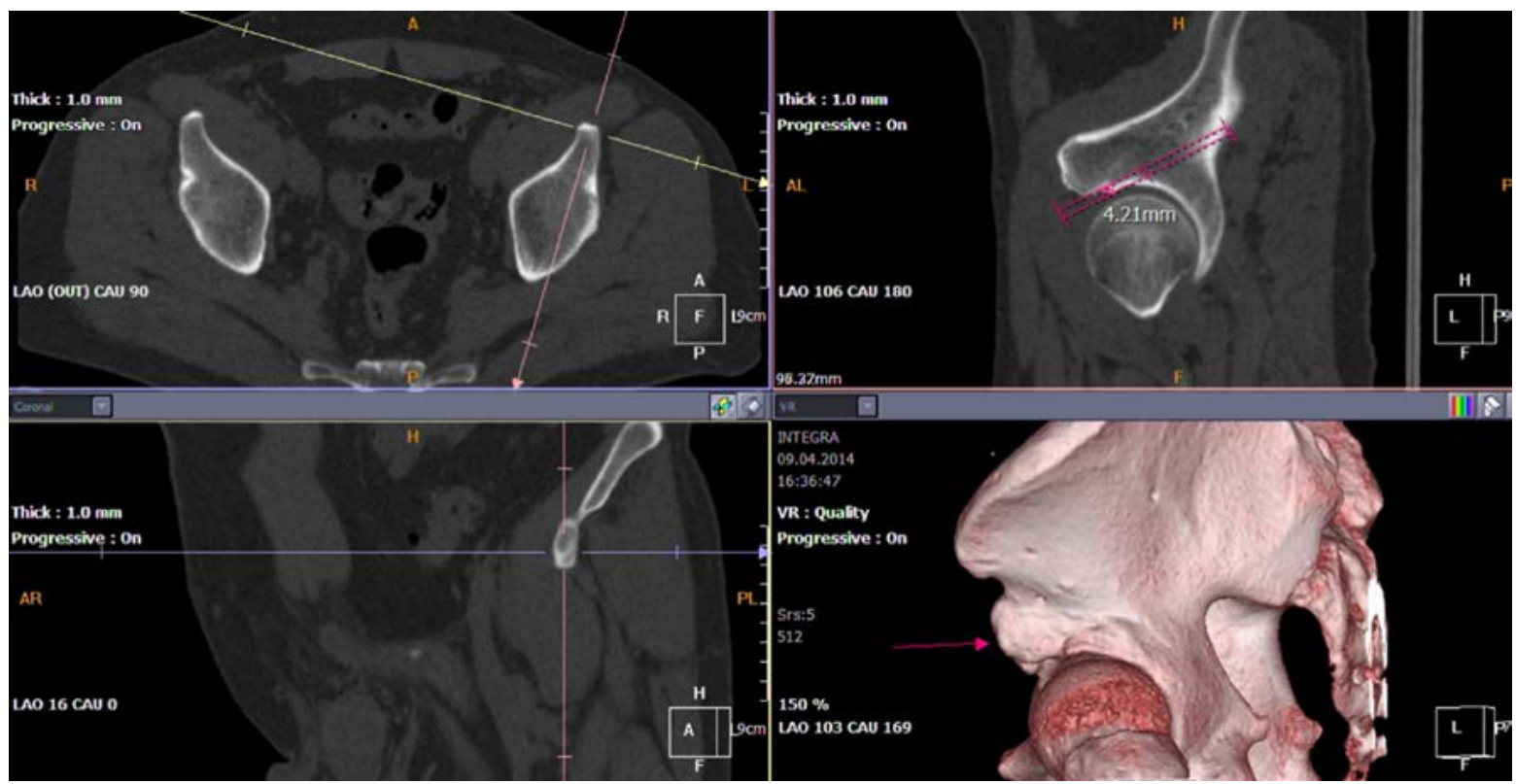

Şekil 18. BT ile normal bireylerde Aiis asetabulum mesafesinin ölçülmesi.

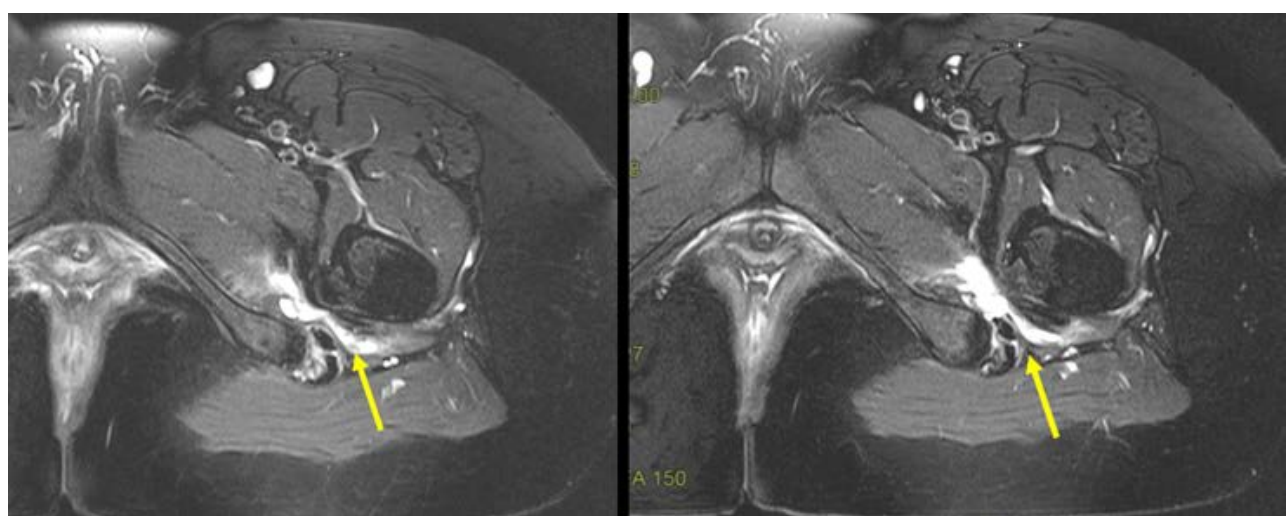

Şekil 19. Aksiyel MR kesitlerinde iskio-femoral mesafede daralma ve kuadratus femoris kasında ödem.

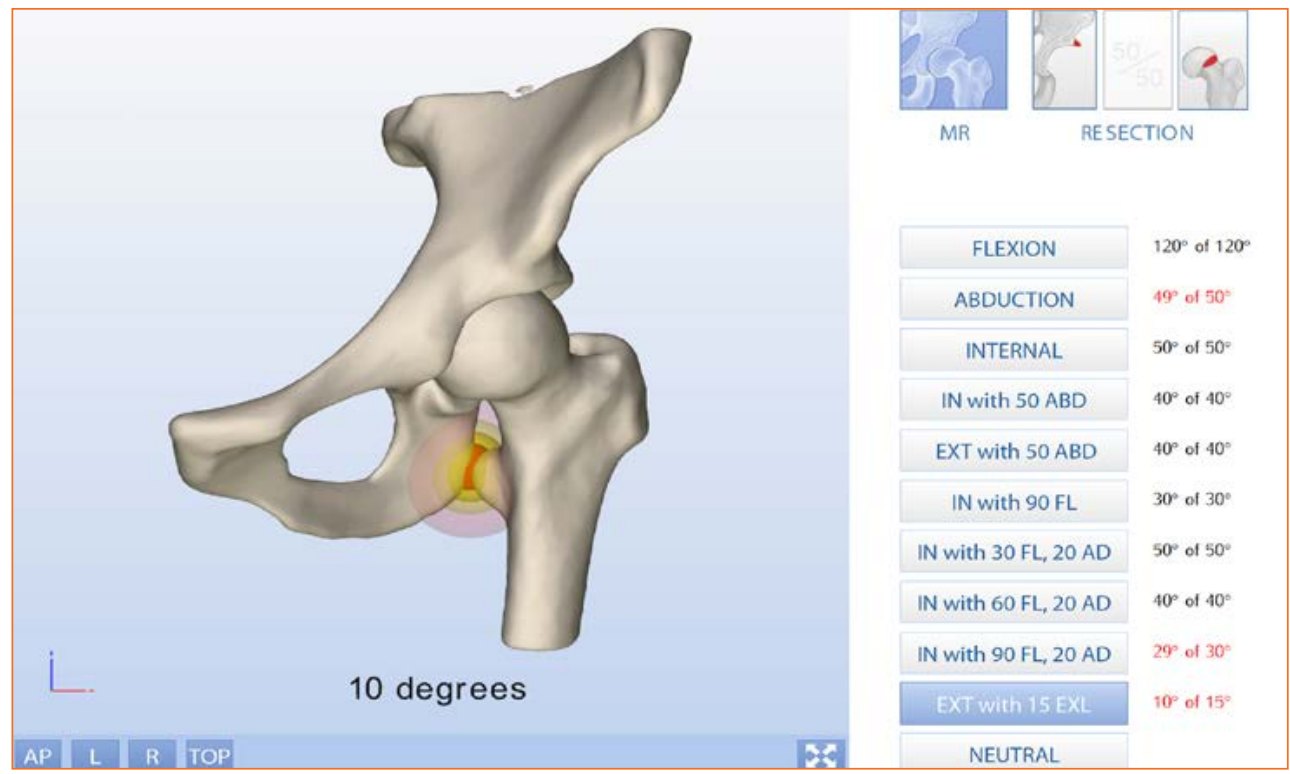

Şekil 20. 3B dinamik değerlendirme ile ekstansiyon - dış rotasyonda iskiofemoral sıkışmanın gösterilmesi. 


\section{KAYNAKLAR}

1. Canham CD, Williams RB, Schiffman $S$, Weinberg EP, Giordano BD. Cumulative Radiation Exposure to Patients Undergoing Arthroscopic Hip Preservation Surgery and Occupational Radiation Exposure to the Surgical Team. Arthroscopy 2015;31(7):1261-8.

2. Grabinski R, Ou D, Saunder K, Rotstein A, Singh P, Pritchard $\mathrm{M}$, O'Donnell J. Protocol for CT in the position of discomfort: preoperative assessment of femoroacetabular impingement how we do it and what the surgeon wants to know. J Med Imaging Radiat Oncol2014;58(6):649-56. Crossref

3. Heyworth BE, Dolan MM, Nguyen JT, Chen NC, Kelly BT. Preoperative three-dimensional $C T$ predicts intraoperative findings in hip arthroscopy. Clin Orthop Relat Res 2012;470(7):1950-7. Crossref

4. Koerner JD, Patel NM, Yoon RS, Sirkin MS, Reilly MC, Liporace FA. Femoral version of the general population: does "normal" vary by gender or ethnicity? J Orthop Trauma 2013;27(6):308-11. Crossref

5. Fabricant PD, Fields KG, Taylor SA, Magennis E, Bedi A, Kelly BT. The effect of femoral and acetabular version on clinical outcomes after arthroscopic femoroacetabular impingement surgery. J Bone Joint Surg Am 2015;97(7):53743. Crossref

6. Dy CJ, Schroder SJ, Thompson MT, Alexander JW, Noble PC. Etiology and severity of impingement injuries of the acetabular labrum: what is the role of femoral morphology? Orthopedics 2012;35(6):e778-84. Crossref

7. Ellis AR, Noble PC, Schroder SJ, Thompson MT, Stocks GW. The cam impinging femur has multiple morphologic abnormalities. J Arthroplasty 2011;26(6 Suppl):59-65. Crossref

8. Akiyama $M$, Nakashima $\mathrm{Y}$, Fujii $\mathrm{M}$, Sato $\mathrm{T}$, Yamamoto $\mathrm{T}$, Mawatari T, Mawatari T, Motomura G, Matsuda S, Iwamoto Y. Femoral anteversion is correlated with acetabular version and coverage in Asian women with anterior and global deficient subgroups of hip dysplasia: a CT study. Skeletal Radiol 2012;41(11):1411-8.

9. Dandachli W, UI Islam S, Tippett R, Hall-Craggs MA, Witt JD. Analysis of acetabular version in the native hip: comparison between 2D axial CT and 3D CT measurements. Skeletal Radiol 2011;40(7):877-83. Crossref

10. Osmani HT, Henckel J, Cobb J, Hart AJ. Native acetabular version: $3 \mathrm{D} C \mathrm{CT}$ analysis of the psoas valley. Hip Int 2013;23(3):274-80. Crossref

11. Tannenbaum EP, Zhang $P$, Maratt JD, Gombera MM, Holcombe SA, Wang SC, Bedi A, Goulet JA. A Computed Tomography Study of Gender Differences in Acetabular Version and Morphology: Implications for Femoroacetabular Impingement. Arthroscopy 2015;31(7):1247-54. Crossref

12. Ross JR, Nepple JJ, Philippon MJ, Kelly BT, Larson $C M$, Bedi A. Effect of changes in pelvic tilt on range of motion to impingement and radiographic parameters of acetabular morphologic characteristics. Am J Sports Med 2014;42(10):2402-9. Crossref

13. Larson CM, Moreau-Gaudry A, Kelly BT, Byrd JW, Tonetti J, Lavallee S, Chabanas L, Barrier G, Bedi A. Are normal hips being labeled as pathologic? A CT-based method for defining normal acetabular coverage. Clin Orthop Relat Res 2015;473(4):1247-54. Crossref

14. Monazzam S, Bomar JD, Cidambi K, Kruk P, Hosalkar $\mathrm{H}$. Lateral center-edge angle on conventional radiography and computed tomography. Clin Orthop Relat Res 2013;471(7):2233-7. Crossref
15. Werner CM, Ramseier LE, Ruckstuhl T, Stromberg J, Copeland CE, Turen CH, Rufibach K, Bouaicha S. Normal values of Wiberg's lateral center-edge angle and Lequesne's acetabular index -a coxometric update. Skeletal Radiol 2012;41(10):1273-8. Crossref

16. Anderson LA, Gililland J, Pelt C, Linford S, Stoddard GJ, Peters $\mathrm{CL}$. Center edge angle measurement for hip preservation surgery: technique and caveats. Orthopedics 2011;34(2):86. Crossref

17. Tannast M, Hanke MS, Zheng G, Steppacher SD, Siebenrock KA. What are the radiographic reference values for acetabular under- and overcoverage? Clin Orthop Relat Res 2015;473(4):1234-46. Crossref

18. Tannast M, Fritsch S, Zheng G, Siebenrock KA, Steppacher SD. Which radiographic hip parameters do not have to be corrected for pelvic rotation and tilt? Clin Orthop Relat Res 2015;473(4):1255-66. Crossref

19. Nötzli HP, Wyss TF, Stoecklin CH, Schmid MR, Treiber K, Hodler J. The contour of the femoral head-neck junction as a predictor for the risk of anterior impingement. J Bone Joint Surg Br 2002;84(4):556-60.

20. Joo JH, Lee SC, Ahn HS, Park JS, Lee WJ, Jung KA. Evaluation of the alpha angle in asymptomatic adult hip joints: analysis of 994 hips. Hip Int 2013;23(4):395-9. Crossref

21. Mimura $T$, Kawasaki $T$, Itakura $S$, Hirata $T$, Fuzikawa $H$, Mori K, Imai S. Prevalence of radiological femoroacetabular impingement in Japanese hip joints: detailed investigation with computed tomography. J Orthop Sci 2015;20(4):64956. Crossref

22. Cadet ER, Babatunde OM, Gorroochurn P, Chan AK, Stancato-Pasik A, Brown M, Johnson S, Kaiser PB, Gardner TR, Ayeni OR. Inter- and intra-observer agreement of femoroacetabular impingement (FAI) parameters comparing plain radiographs and advanced, 3D computed tomographic (CT)-generated hip models in a surgical patient cohort. Knee Surg Sports Traumatol Arthrosc 2014. [Epub ahead of print]

23. Beaulé PE, Zaragoza E, Motamedi K, Copelan N, Dorey FJ. Three-dimensional computed tomography of the hip in the assessment of femoroacetabular impingement. J Orthop Res. 2005;23(6):1286-92.

24. Eijer H, Leunig M, Mahomed N, Ganz R. Cross table lateral radiographs for screening of anterior femoral head-neck offset in patients with femoro-acetabular impingement. Hip Int 2001;11:37-41.

25. Espié $A$, Chaput $B$, Murgier J, Bayle-Iniguez X, Elia F, Chiron P. $45^{\circ}-45^{\circ}-30^{\circ}$ Frog-leg radiograph for diagnosing cam-type anterior femoroacetabular impingement: Reproducibility and thresholds. Orthopaedics \& traumatology, surgery \& research: Orthop Traumatol Surg Res 2014;100(8):843-8. Crossref

26. Nemtala F, Mardones RM, Tomic A. Anterior and Posterior Femoral Head-Neck Offset Ratio in the Cam Impingement. Cartilage 2010;1(3):238-41. Crossref

27. Bouma HW, Hogervorst $T$, Audenaert E, Krekel $P$, van Kampen PM. Can combining femoral and acetabular morphology parameters improve the characterization of femoroacetabular impingement? Clin Orthop Relat Res 2015;473(4):1396-403. Crossref

28. Rego PR, Mascarenhas V, Oliveira FS, Pinto PC, Gaspar A, Ovidio J, Collado DG. Morphologic and angular planning for cam resection in femoro-acetabular impingement: value of the omega angle. Int Orthop 2015. [Epub ahead of print] 
29. Ergen FB, Vudalı S, Sanverdi E, Dolgun A, Aydıngöz Ü. CT assessment of asymptomatic hip joints for the background of femoroacetabular impingement morphology. Diagn Interv Radiol 2014;20(3):271-6. Crossref

30. Hack K, Di Primio G, Rakhra K, Beaulé PE. Prevalence of cam-type femoroacetabular impingement morphology in asymptomatic volunteers. J Bone Joint Surg Am 2010;92(14):2436-44. Crossref

31. Kapron AL, Anderson AE, Aoki SK, Phillips LG, Petron DJ, Toth $\mathrm{R}$, Peters CL. Radiographic prevalence of femoroacetabular impingement in collegiate football players: AAOS Exhibit Selection. J Bone Joint Surg Am 2011;93(19):e111(1-10). Crossref

32. Kim J, Choi JA, Lee E, Lee KR. Prevalence of Imaging Features on CT Thought to Be Associated With Femoroacetabular Impingement: A Retrospective Analysis of 473 Asymptomatic Adult Hip Joints. AJR Am J Roentgenol 2015;205(1):W100-5. Crossref

33. MelladoJM, Radi N. Cam-type deformities: Concepts, criteria, and multidetector CT features. Radiologia 2015;57(3):21324. Crossref

34. Leunig M, Mast NH, Impellizerri FM, Ganz R, Panaro C. Arthroscopic appearance and treatment of impingement cysts at femoral head-neck junction. Arthroscopy 2012;28(1):6673. Crossref

35. Cvetanovich GL, Harris JD, Erickson BJ, Bach BR, Jr, BushJoseph CA, Nho SJ. Revision Hip Arthroscopy: A Systematic Review of Diagnoses, Operative Findings, and Outcomes. Arthroscopy 2015;31(7):1382-90. Crossref

36. Sardana V, Philippon MJ, de Sa D, Bedi A, Ye L, Simunovic $\mathrm{N}$, Ayeni OR. Revision Hip Arthroscopy Indications and Outcomes: A Systematic Review. Arthroscopy 2015;31(10):2047-55. Crossref

37. Bedi A, Dolan M, Magennis E, Lipman J, Buly R, Kelly BT. Computer-assisted modeling of osseous impingement and resection in femoroacetabular impingement. Arthroscopy 2012;28(2):204-10. Crossref

38. Roling MA, Visser MI, Oei EH, Pilot P, Kleinrensink GJ, Bloem RM. A quantitative non-invasive assessment of femoroacetabular impingement with CT-based dynamic simulation -cadaveric validation study. BMC Musculoskelet Disord 2015;16:50. Crossref

39. Milone MT, Bedi A, Poultsides L, Magennis E, Byrd JW, Larson CM, Kelly BT. Novel CT-based three-dimensional software improves the characterization of cam morphology. Clinical orthopaedics and related research 2013;471(8):2484-91. Crossref
40. Wassilew GI, Janz V, Heller MO, Tohtz S, Rogalla P, Hein $P$, Perka C. Real time visualization of femoroacetabular impingement and subluxation using 320-slice computed tomography. J Orthop Res 2013;31(2):275-81. Crossref

41. Ha YC, Choi JA, Lee YK, Kim JY, Koo KH, Lee GY, Kang HS. The diagnostic value of direct CT arthrography using MDCT in the evaluation of acetabular labral tear: with arthroscopic correlation. Skeletal Radiol 2013;42(5):681-8. Crossref

42. Sahin $M$, Calisir $C$, Omeroglu $H$, Inan $U$, Mutlu F, Kaya $T$. Evaluation of Labral Pathology and Hip Articular Cartilage in Patients with Femoroacetabular Impingement (FAI): Comparison of Multidetector CT Arthrography and MR Arthrography. Pol J Radiol 2014;79:374-80. Crossref

43. Henak CR, Abraham CL, Peters CL, Sanders RK, Weiss $\mathrm{JA}$, Anderson AE. Computed tomography arthrography with traction in the human hip for three-dimensional reconstruction of cartilage and the acetabular labrum. Clin Radiol 2014;69(10):e381-91. Crossref

44. Smith TO, Simpson M, Ejindu V, Hing CB. The diagnostic test accuracy of magnetic resonance imaging, magnetic resonance arthrography and computer tomography in the detection of chondral lesions of the hip. Eur J Orthop Surg Traumatol 2013;23(3):335-44. Crossref

45. Amar E, Warschawski Y, Sharfman ZT, Martin HD, Safran MR, Rath E. Pathological findings in patients with low anterior inferior iliac spine impingement. Surg Radiol Anat 2015. [Epub ahead of print]

46. Hetsroni I, Poultsides L, Bedi A, Larson CM, Kelly BT. Anterior inferior iliac spine morphology correlates with hip range of motion: a classification system and dynamic model. Clin Orthop Relat Res 2013;471(8):2497-503. Crossref

47. Sanverdi E, Gurses MA, Akcalar Yildirim S, Kayaalp A, Tandogan R, Alibek S, Yildirim-Eryilmaz N, editors. Normal Values of the Subspinal Interval and the Angle of AllS Acetabulum: A Multicentric CT Study. Chicago, IL, USA: 100th Annual Meeting of Radiological Society of North America; 2014. http://archive.rsna.org/2014/14016475. html Accessed: January 29, 2016

48. Stafford GH, Villar RN. Ischiofemoral impingement. J Bone Joint Surg Br 2011;93(10):1300-2. Crossref

49. Torriani M, Souto SC, Thomas BJ, Ouellette H, Bredella MA. Ischiofemoral impingement syndrome: an entity with hip pain and abnormalities of the quadratus femoris muscle. AJR Am J Roentgenol 2009;193(1):186-90. Crossref 